\title{
The Economic Impact of Price Controls on China's Natural Gas Supply Chain
}

Bertrand Rioux, Philipp Galkin, Frederic Murphy, Axel Pierru, Artem Malov, Felipe Feijoo Palacios, Yan Li and Kang Wu 


\section{About KAPSARC}

The King Abdullah Petroleum Studies and Research Center (KAPSARC) is a non-profit global institution dedicated to independent research into energy economics, policy, technology and the environment, across all types of energy. KAPSARC's mandate is to advance the understanding of energy challenges and opportunities facing the world today and tomorrow, through unbiased, independent, and high-caliber research for the benefit of society. KAPSARC is located in Riyadh, Saudi Arabia.

\section{Legal Notice}

(c) Copyright 2018 King Abdullah Petroleum Studies and Research Center (KAPSARC). No portion of this document may be reproduced or utilized without the proper attribution to KAPSARC. 


\section{Key Points}

espite significant progress made by China in liberalizing its natural gas market, certain key areas such as market access and pricing mechanisms remain heavily monopolized or controlled by the government. To assess how such distortions impact the market, we developed a Mixed

Complementarity Problem model of China's natural gas supply industry, calibrated to 2015 data. We find that:

Lifting the price caps for regulated natural gas demand sectors could yield a 4.4 percent reduction in total system cost (amounting to $\$ 1.3$ billion annual savings) and reduce the national average marginal supply cost by 14 percent. Combined with improved third-party access to the pipeline and regasification infrastructure, the price reform would result in a $\$ 2.2$ billion (7.6 percent) saving in total system costs. These adjustments are the result of Chinese suppliers reducing the priority of unregulated liquefied natural gas (LNG) supplies, including domestic liquefaction and imports, with trucked LNG replaced by pipeline distribution.

The current regulatory environment facilitates fragmented regional gas markets, whereas abolishing price caps and granting access to pipelines would lead to the unification of the national gas market and increased competition between pipeline imports from the west and coastal LNG imports.

The LNG industry - both imports and domestic - would be negatively affected by the proposed reforms, as market players would gain more flexibility in their logistics and would utilize lower cost supply pathways.

Our analysis also shows that the existing market structure, particularly heavy market concentration and regional domination of national oil companies (NOCs), limits the impacts of natural gas market liberalization. 


\section{Executive Summary}

$\mathbf{R}$ eforming the pricing mechanism and ensuring efficient third-party access to infrastructure have been the top priorities of China's policy agenda for the natural gas industry. While prices for unconventional gas supplies and liquefied natural gas (LNG) imports have been largely liberalized (settled by sellers and buyers through negotiations), certain consumer groups (commercial and residential demand, small industrial users) and modes of delivery (pipeline) are still subject to fixed prices or price caps. These price distortions incentivize profit-maximizing firms to alter their operational, logistic and investment strategies to avoid supplying gas at capped prices, leading to the cross-subsidization of lower-priced regulated demand sectors, with higher tariffs charged in deregulated markets. Limited access to midstream infrastructure further distorts logistics patterns and leads to a suboptimal market structure and a less efficient resource allocation nationally.

To estimate the magnitude of such distortions and potential gains from liberalization reforms, we developed a single-period equilibrium model that provides a short-term perspective on China's gas market. Key model output elements include total production, domestic liquefaction, pipeline and LNG imports, average marginal cost (weighted by provincial demand), and total systems cost. The model is formulated as a mixed complementarity problem (MCP) and represents the profit-maximizing behavior of price-taking suppliers - three large national oil companies (NOCs) and smaller fringe suppliers - with some market segments subject to price caps. The model is calibrated to simulate the structure of China's provincial natural gas supply market in 2015. Scenarios include lifting the price caps and providing all market players with equal access to pipelines and regasification infrastructure.

We find that lifting the price caps for regulated natural gas demand sectors in 2015 would have resulted in a 14 percent reduction in marginal supply costs and decreased the total system cost by 4.7 percent or $\$ 1.4$ billion. These efficiency gains primarily occur as a result of optimized logistics reduced domestic liquefaction and LNG trucking - and import patterns, as market participants no longer prioritize more expensive delivery pathways to target unregulated market segments.

The impact of eliminating price controls is magnified when all market players are granted access to midstream infrastructure. These two initiatives combined could have saved $\$ 2.2$ billion (7.6 percent of total cost) and reduced the average spot prices across provinces by 16 percent. Opening the market eliminates the use of domestic LNG to skirt the price caps and lowers the marginal cost of supply. In some central provinces, the resulting price declines lead to prices below the government-enforced price cap, increasing the competitiveness of natural gas in the provincial fuel mix. Increased flexibility in logistics induces competition among import sources and facilitates the penetration of cheaper pipeline imports to central and even eastern provinces. The impact of third-party-access reform, on its own, is less pronounced: the spot prices record minimum changes, and total cost savings are below $\$ 1$ billion.

The current regulatory environment facilitates the regionalization of China's gas market and favors the LNG industry, both its imported and domestic liquefaction segments. Conversely, the proposed reform initiatives tie segregated regional markets together through optimized logistics patterns and increase the competitiveness of pipeline imports. In a highly concentrated environment where a particular NOC dominates many regional markets, such reforms will likely alter the competitive landscape significantly and could face opposition from major players. The potential for the players to exercise market power is an aspect of the market not addressed in this study. 


\section{Chinese Natural Gas Market}

\section{The role of natural gas in China's energy mix}

Natural gas production in China has grown rapidly in the 21st century, increasing over 500 percent from $27.2 \mathrm{bcm}$ in 2000 to $136.9 \mathrm{bcm}$ in 2016. Yet the growth in demand has outpaced supply growth, increasing about 850 percent over the same period. Imports totaling 74.6 billion cubic meters $(\mathrm{bcm})$ in 2016, or 36 percent of total consumption (CEIC 2017), have filled the gap between supply and demand. This gap is projected to continue increasing, reaching $210 \mathrm{bcm}$ by 2020 (Wang et al. 2013). The share of net gas imports in total consumption has jumped further, to over 40 percent in 2017 from a surge in LNG imports and, to a lesser extent, pipeline gas imports.

At 6.4 percent of total energy consumption natural gas accounts for a modest share of China's energy mix. This is despite China's rapid development and a significant domestic resource base: 40 trillion cubic meters of conventionally recoverable resources according to the data from Ministry of Land and Resources (MLR 2015). In 2016 coal still dominated China's energy mix with a share of 62 percent.

Analysts cite low efficiency, opaque and complex pricing mechanisms, problematic transportation and organizational inflexibility (Shell and DRC 2017; Li 2015; Wang and Li 2014) as major problems that have led to a recent slowdown in production growth and impeded further development of the sector, including the ability of gas to compete with other fuels. These issues have to be addressed in order to achieve the ambitious targets Chinese policymakers have set for the industry (NDRC 2016, 2017):

A share of 10 percent in total energy consumption by 2020 and 15 percent by 2030 .

Increasing annual demand to $360 \mathrm{bcm}$ by 2020 .
Due to economic, infrastructure and energy security considerations, incremental imports alone cannot meet such ambitious demand targets. The 13th FiveYear Plan for Natural Gas Development outlines a substantial build-up in capacity, particularly in the natural gas power generation and pipeline transportation segments (NDRC 2016). There is also significant potential to optimize the utilization of existing capacities in the domestic natural gas upstream and midstream sectors.

\section{The structure of upstream and transportation sectors}

Three large NOCs dominate China's natural gas production and transportation infrastructure: China National Petroleum Corporation (CNPC), China Petrochemical Corporation (Sinopec) and China National Offshore Oil Corporation (CNOOC). A number of smaller private firms, often in partnership with the NOCs, engage in production - primarily, in the unconventional segment - as well as in LNG liquefaction, transportation, and regasification.

China's domestic supply consists primarily of onshore conventional production (80.9 percent) dominated by the NOCs, offshore gas (9.5 percent) operated by $\mathrm{CNOOC}$ and its joint ventures, and coal-bed methane (CBM) (3.6 percent). CBM includes vented coal-mine methane (CMM) extracted by domestic coal producers (about 45 percent of total) along with CNPC and other domestic and foreign private companies. Recently, power generators, coal companies and gas distributors have increased synthetic natural gas (SNG) production to about 1 percent of supplies (SIA 2017).

CNPC, Sinopec and Shell, as well as national and provincial state-owned enterprises (SOEs), have developed unconventional shale gas, providing 3.3 percent of domestic production. Although 
China possesses vast unconventional resources, geological and technological challenges hinder their development, making it difficult to repeat the success of the recent U.S. shale revolution. Ownership claims to the more accessible shale gas plays have been largely limited to China's NOCs, which limits future investments and innovation efforts (TLG 2014).

China's gas pipeline imports totaled $34.2 \mathrm{bcm}$ in 2015 (CEIC 2017). They are dominated by CNPC, which controls imports from Central Asia (88.3 percent of the total volume). Smaller volumes are imported via the Myanmar pipeline, and new contracts with Russia are expected to materialize in the foreseeable future. The NOCs also dominated LNG imports at around 27.2 bcm in 2015 (SIA 2017). However, provincial SOEs and private companies are increasing their participation following recent market reforms (NEA 2014; NDRC 2014).

The NOCs own and operate the major domestic pipelines, consisting of 16 national trunk pipelines and over 80 sub-national trunk pipelines. The gas distribution market comprises large industrial and commercial consumers, provincial SOEs, private companies, joint ventures and downstream subsidiaries of NOCs. 


\section{Regulatory Environment and Reform Initiatives}

\section{Background}

China has made significant progress on the path towards transforming its natural gas sector from being highly centralized and centrally planned to market-driven. Originally under the planned economic system, the government combined the functions of the owner, investor, operator and regulator. Various ministries were responsible for exploration, development and transportation of natural gas, and the government set the prices. The government changed the structure of the industry to be more market-oriented. Since then, China has created three large NOCs that dominate the natural gas production and transportation infrastructure, publicly listed them on foreign markets, introduced a licensing system, and allowed private capital to explore for conventional gas. The government also liberalized the unconventional gas segment and gradually relaxed its price controls. These measures have contributed greatly to the development of the sector (Hu and Xu 2013; Paltsev and Zhang 2015).

As a result of the administrative reforms, the National Development and Reform Commission (NDRC) and the National Energy Administration (NEA) emerged as major industrial regulators across the national natural gas supply chain. The NDRC is responsible for the overall strategy and planning, macro-policy, pricing and fiscal policy, overall reform direction and approval of major projects (Shell and DRC 2017). The NEA primarily focuses on industrial policy and supervision. In the upstream sector, the Ministry of Land and Resources (MLR) defines the policies for mineral rights allocation, exploration of resources and foreign cooperation, and drafts relevant legislation and development plans. Provincial governments are more involved in the midstream and downstream sectors where they can adjust regulated prices within the established boundaries and are responsible for monitoring, inspection and supervision.

The problem the Chinese government faces is that parts of the natural gas market can be made workably competitive while other parts are natural monopolies. This is best understood through the structure of gas markets in other countries.

Exploration and production is competitive in countries with multiple sources of supply and a resource base not dominated by a few players. Gas supply is a competitive market in the United States, with a large number of producers and multiple supply regions. With its large and diverse resource base, China has the potential to be more like the U.S. than Europe, which has the problem that Russia provides one-third of the supply with an even more dominant share in Central Europe. Like Europe, China's contracts with Russia can lead to regions with a dominant supplier. Furthermore, the practice of favoring the dominant firms has not led to enough producers in each region to enable reliable competition in supply. LNG imports, on the other hand, can be workably competitive, as the LNG market has evolved to include a large number of players in a growing spot market.

The failure of the early cost-based regulations in China parallels the unsuccessful attempts by the Federal Power Commission in the U.S., now the Federal Energy Regulatory Commission (FERC), to use cost as the basis for regulating prices at the wellhead (MacAvoy 1970). Using cost to regulate prices does not work as finding gas is a chancy business: including the costs of unsuccessful exploration attempts in the cost of gas produced means subsidizing unskilled exploration companies. However, not including these costs excludes a legitimate cost of doing business. 
Fixing a price ceiling for gas has its own problems. The ceiling works as long as demand is below the level of production of associated gas that would otherwise have been flared. Here any price is better than the cost of flaring. However, once nonassociated gas production is at capacity, regulatory inertia can keep prices too low. That happened in the U.S. in the 1970s when massive shortages led to the temporary shutdown of major industries and to the abandonment of price controls in the form of ceilings. In China's case, a sufficiently low price can lead to a supply shortage and an increase in government-subsidized imports as the development of domestic resources falls short.

The approach to blending markets with regulated monopolies taken in the U.S. is to require the pipelines to maintain open access and treat all customers equally. FERC monitors the pipeline contracts to ensure the pipeline companies do not buy too much capacity and return too much market power to the pipelines. The EU supplemented the economic rationale behind unbundling (vertical disintegration) and ensuring open access to infrastructure with the intention to create an integrated European market and establish a supranational mechanism to guarantee the security of supply (Lowe 2007). Hence, the authorities drive pipeline infrastructure expansion, allocating construction and maintenance contracts on the cost-plus basis. The market drives investment in LNG and storage terminals. Regulators ensure third-party access to capacities but do not interfere in pricing mechanisms.

The U.S. and EU experiences highlight that there is no single approach to regulating gas markets. China has to strike its own balance between regulating and using markets to achieve economic efficiencies.

The recent transition of China's economy, from the explosive growth in industrialization to a 'new normal' phase that focuses on consumption, has relieved some pressures on energy supplies and created an opportunity to accelerate reforms in the natural gas sector. There is the potential for substantial progress in more market-oriented pricing mechanisms and stimulating competition and efficiency through reducing barriers to market access. Here we examine the economic consequences of the current market rules and regulations.

\section{Price reform}

Tight control of natural gas prices in China has been a major hindrance to the development of available resources, competitiveness with other fuels and overall market efficiency (Fang and Ma 2017). In recent years, the Chinese government has attempted to remedy the situation by introducing a number of natural gas pricing reform initiatives.

Before 2013, ex-plant prices consisting of wellhead costs, processing fees and margins, had been set by the NDRC for each basin based on the type of consumer: fertilizer, power, industry and residential. Producers and consumers could negotiate within $+/-10$ percent range of the set price. However, the cost-plus approach was insufficient to compensate suppliers for purchasing imported pipeline gas and LNG and did not provide sufficient incentives for infrastructure investment.

The government introduced major sectoral reforms in 2013 to address fundamental pricing issues. The price controls for all types of gas supplied by pipeline switched from the wellhead to the city gate. The city gate pricing mechanism consisted of a two-tiered price ceiling for a base level of demand (fixed at the 2012 demand) and incremental demand, which varied significantly by 
province (Aolin et al. 2015). Prices for offshore, domestic and imported LNG and unconventional resources became exempt from price controls unless delivered via regional pipeline networks (Paltsev and Zhang 2015). CNOOC received exclusive rights to buy offshore gas from independent producers.

Recent measures aimed at rationalizing nonresidential natural gas prices (NDRC 2015) represent the seventh adjustment to prices and formalize the current pricing mechanism. In 2015, the direct consumer category - government approved large industrial users, except for the chemical industry - was exempt from price controls. This has motivated China's NOCs to lobby to have their large consumers, particularly in the strategic industrial provinces, categorized as direct supply. The government has also implemented reforms to lift the preferential gas prices paid by chemical fertilizer producers (He et al. 2017).

However, as the market matures, the city gate and distribution gas prices need to be reformed. In 2015 the two-tiered price ceiling was also lifted, resulting in a single price cap for city gate consumers in each province. Analysts emphasized the positive effect of the policies on fuel switching and consumption growth (SIA 2015; Chen 2016). However, the 2015 reform was also a step backward in the transparency and stability of the pricing mechanism due to its delinking from oil prices.

In 2017, China kick-started a pilot program to rationalize city gate prices in Fujian province following the corresponding notice released by NDRC in late 2016 (Daiwa 2016). At the same time, the government announced that it would improve pricing mechanisms for urban gas networks in an effort to increase the competitiveness of gas and reduce the inflated prices and profits received by distribution companies (China Daily 2017).
The current pricing structure also leaves a number of unresolved market distortions. Capped prices for residential gas consumption (as a part of the city gate price controls) are substantially lower than deregulated prices for large industrial consumers - the opposite pricing structure compared to the Organization for Economic Cooperation and Development countries. Such price differentials occur when the regional caps are lower than the marginal cost of supplied gas. Suppliers' attempt to compensate for such losses by charging higher prices to industrial consumers in deregulated markets where possible, thus exacerbating these price differentials and leading to crosssubsidization between various demand sectors. Price caps imposed on particular demand sectors and supply sources can also affect suppliers' operational (choice of the market, region, supply path) and investment decisions, potentially causing deviations from the most efficient resource allocation nationally.

Without further reforms across the natural gas supply chain, China is likely to miss its planned target share of natural gas in total consumption by the end of the decade (SIA 2017). Reducing the price spread between different market segments that occurs due to government price interventions in certain markets can be instrumental in supporting incremental demand. This will require further liberalization of city gate prices, which, in turn, would help to address crosssubsidization issues and reduce the need for government subsidies.

\section{Third-party access to midstream infrastructure}

Historically, the Ministry of Petroleum Industry had administered the construction and operation of natural gas pipelines. These functions were then transferred to the NOCs, which retain their 
monopolistic control over pipelines and dominate other midstream infrastructure.

At the beginning of China's 12th five-year planning period, the government initiated a series of measures aimed at fair participation in pipeline construction, facilitating third-party access to pipelines and improving the supervision of midstream operations. In 2014, NDRC issued the Management Measures of Natural Gas Infrastructure Construction and Operation aimed at encouraging various types of investment and increasing operational transparency (NDRC 2014). In the same year, NEA released the Measures for Natural Gas Infrastructure Construction and Operation requiring that pipeline owners/operators provide third parties with access to their spare capacity and associated services, including gasification, storage and transportation (NEA 2014). However, this initiative has not gained much traction due to the reluctance of NOCs to share their infrastructure with competitors and their claimed lack of spare pipeline capacity (Chen 2016).

In the LNG import segment, only eight companies managed to take advantage of the third-party access (TPA) policy since the guidelines were released, receiving imported LNG at NOC-owned terminals
(Interfax 2017). Independent gas companies have had to resort to building their own terminals, duplicating the existing underutilized infrastructure operated by NOCs (Trusted Sources 2016).

Limited success in implementing the TPA initiatives prompted the search for structural solutions to the problem. Establishing an independent pipeline operator could facilitate more efficient utilization and pricing of gas pipelines and LNG terminals (Xu et al. 2017). Other supporting measures may include liberalizing pipeline transmission fees and an independent assessment of excess infrastructure capacities (Shell and DRC 2017). Progress continued in 2017, including the audit of pipeline costs across the three large NOCs (Reuters 2017) and an announcement of policies to open access to third parties, which included separating the pipeline business from final sales (China Daily 2017). 


\section{Description of the Model}

\section{Modeling approach}

We use an equilibrium model to present a snapshot of China's natural gas market. As with the other sectors of the KAPSARC Energy Model of China (Rioux et al. 2016; Rioux et al. 2017) and the family of KAPSARC energy models (Matar et al. 2015; Matar et al. 2017), the representation of natural gas captures the regulations that shape the market in China. It can also estimate the impacts of those regulations on the efficiency of China's gas market. This ability to model regulations in the microeconomy is unique to this family of models.

In terms of the physical features of the Chinese gas market, our model is similar to the optimization model developed by Zhang et al. (2015). They apply detailed infrastructure representations to investigate how supply costs impact the optimal development of China's natural gas infrastructure, whereas our model focuses on how existing government regulations influence the market equilibrium.

The model is a single-period equilibrium model offering a short-term perspective of China's gas market, calibrated to historical demands and considering only existing capacity with no new investment. We represent the profit-maximizing behavior of price-taking suppliers - three large NOCs and smaller fringe suppliers - with some market segments subject to price caps. The model is formulated as an MCP with representations of the regional price caps for market segments subject to different regulations (chemical and city gate pipeline deliveries), and the supply obligations imposed by the government.

In a deregulated market with fixed demands, minimizing cost is equivalent to maximizing profits, as all supplies are priced at their marginal costs of delivery. This is not true of a regulated environment (i.e., certain segments of the Chinese gas market that operate under the government-controlled pricing regime) since some deliveries are made at capped prices, which can fall below the marginal supply costs. Consequently, there is an incentive to supply the more profitable market segments. We therefore adjust the cost-minimization objective function by including the profits lost when selling at capped prices, below marginal costs. In other words, the firms maximize their profits knowing that in some situations they will get lower revenues due to the price caps.

In response to the price caps, suppliers might alter their logistics decisions (for example, switching to more expensive LNG in order to operate in a more lucrative unregulated market). From a cost minimization perspective, this can increase the overall supply cost. In practice, the government enforces contractual obligations requiring suppliers to deliver pipeline gas at capped prices. In the model, we assume that the NOCs engage in exchanges to reduce the total cost of the aggregate contractual obligations for each regulated market segment.

The model includes the production of conventional, offshore, unconventional, and coal bed methane (surface production and coal-mine extraction), plus pipeline and LNG imports. The midstream infrastructure comprises the pipeline and LNG facilities needed to move gas from supply regions to demand locations. Because of the regulations, this infrastructure is distinguished by the various gas types and market segments. To capture the incentives of the large firms, we differentiate the pipelines by the large NOCs that own them. We use this ownership structure in scenarios with producers restricting TPA to their facilities for other producers.

Appendix 1 contains the detailed mathematical formulation of the model. 
(a)

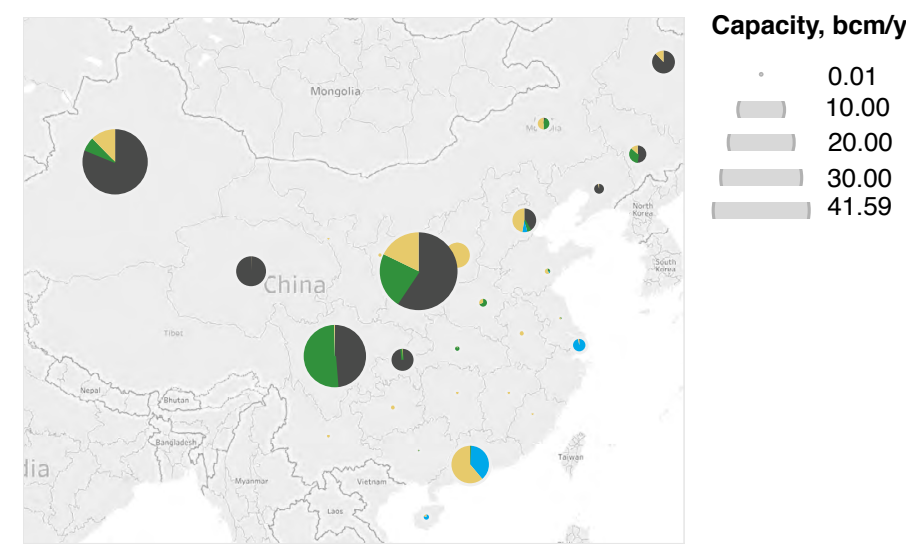

(b)

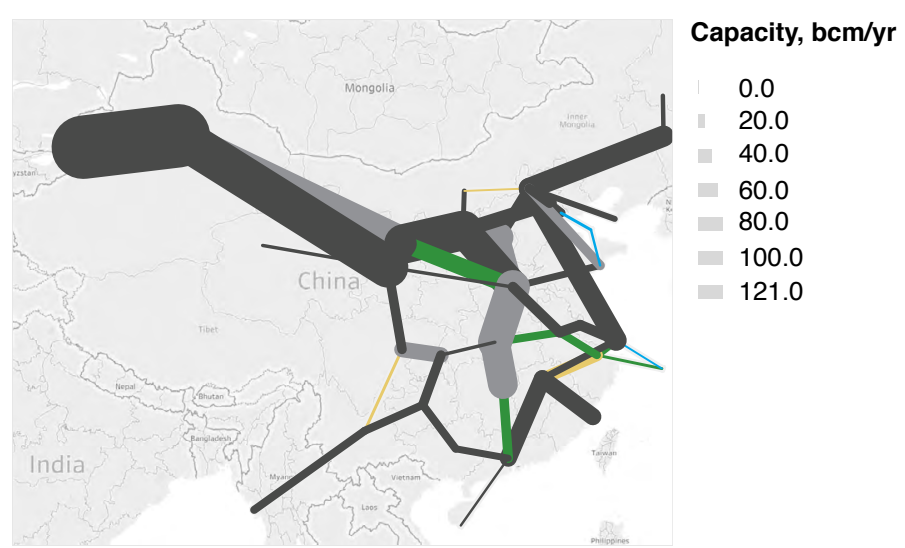

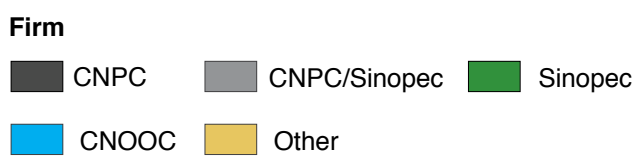

Figure 1. Firm production (a) and aggregate pipeline capacity (b) in 2015.

Source: IHS, Ministry of Land and Resources of China, KAPSARC research.

Calibrating supply and demand

We have calibrated the model to simulate the structure of China's provincial natural gas supply market in 2015. The model represents three large NOCs and smaller independent producers, supplying from conventional, unconventional, offshore, CBM, CMM and import sources. The model includes 31 provincial supply and demand nodes, two offshore supply nodes (Xihu and Bozhong) and two pipeline import nodes (Myanmar and Central Asia) along China's international borders. All coastal nodes can import LNG.

We have fixed natural gas production levels from existing reserves to values based on production profiles for associated, conventional, offshore and unconventional natural gas reserves estimated using IHS (Vantage) data and QUE\$TOR industrial software. We have derived marginal production costs from the same software, with associated gas production from oil fields assumed to have zero marginal cost. We have constructed production profiles for CBM using data from the China Mineral Resources Report and other sources (MLR of China
2015; Qin and Ye 2015; Mu et al. 2015). We have modeled the maximum production of $\mathrm{CMM}$ as a fixed proportion of the total coal production in 2015. Appendix 3 contains a detailed description of the methodology, tools and sources used.

Figure 1a maps the 2015 provincial production estimates by firm. Figure $1 \mathrm{~b}$ shows the interprovincial pipeline capacity owned by each firm in 2015, compiled using midstream data from IHS (Edin). All production and import volumes, as well as pipeline capacity, are reported in billions of cubic meters $(\mathrm{bcm})$ per year.

Demand is fixed and segmented into three markets: large industrial consumers (direct), the chemical industry and others, aggregated into the city gate category. Table A2-1 in Appendix 2 lists the provincial demands by market segment. Gas delivered by pipeline to the chemical industry is subject to a flat national price cap of $\$ 136.5$ / thousand cubic meters $(\mathrm{kcm})$. Table 1 lists the provincial price caps for pipeline deliveries to city gate consumers. 
We have calibrated the total provincial demand to the natural gas balance sheet (CEIC 2017), using the 'Industry Use as Material' category for chemical industry demand. As gas supplies to direct industrial consumers are not reported, we represent the demands in market segments by dividing provinces into two groups according to their industrial structure. We set the proportion of industrial demand assigned to direct market demand to 50 percent in industrialized provinces with higher gas consumption, and 20 percent for less industrialized provinces. The proportion of direct market demand in non-chemical industrial use is approximately 45 percent, in line with the levels reported by PetroChina (China Daily 2015). We assign all remaining demand to the city gate category.
Given that price regulations can incentivize firms to prioritize unregulated LNG deliveries, the NOCs are contractually obliged to meet a specified amount of demand, even if they incur losses. Private companies are excluded from these obligations. Since actual pipeline delivery requirements are not reported, we use these requirements as a calibration parameter to adjust the equilibrium point in our model of the regulated market. Without the obligation to supply from domestic sources, domestic liquefaction, LNG imports and deliveries would exceed levels reported in 2015. Whereas, when the obligations are set too high, LNG deliveries fall short of reported values. During the calibration phase, we found that setting obligations to an average of 63 percent of demand in the provincial regulated market segments provided an equilibrium that represents the 2015 market structure.

Table 1. Provincial city gate price caps (excluding VAT).

\begin{tabular}{l|l|l|l} 
Province & Price cap $\mathbf{( \$ \mathbf { k c m } )}$ & Province & Price cap $\mathbf{( \$ / k c m )}$ \\
\hline Anhui & 396 & Jiangsu & 406 \\
\hline Beijing & 384 & Jiangxi & 378 \\
\hline Chongqing & 332 & Jilin & 350 \\
\hline Fujian & 378 & Liaoning & 381 \\
\hline Gansu & 303 & Ningxia & 314 \\
\hline Guangdong & 409 & Qinghai & 280 \\
\hline Guangxi & 385 & Shaanxi & 290 \\
\hline Guizhou & 342 & Shandong & 381 \\
\hline Hainan & 332 & Shanghai & 409 \\
\hline Hebei & 381 & Shanxi & 371 \\
\hline Heilongjiang & 350 & Sichuan & 334 \\
\hline Henan & 385 & Tianjin & 384 \\
\hline Hubei & 378 & Xinjiang & 263 \\
\hline Hunan & 378 & Yunnan & 342 \\
\hline Inner Mongolia & 290 & Zhejiang & 408
\end{tabular}

Source: NDRC 2015. 


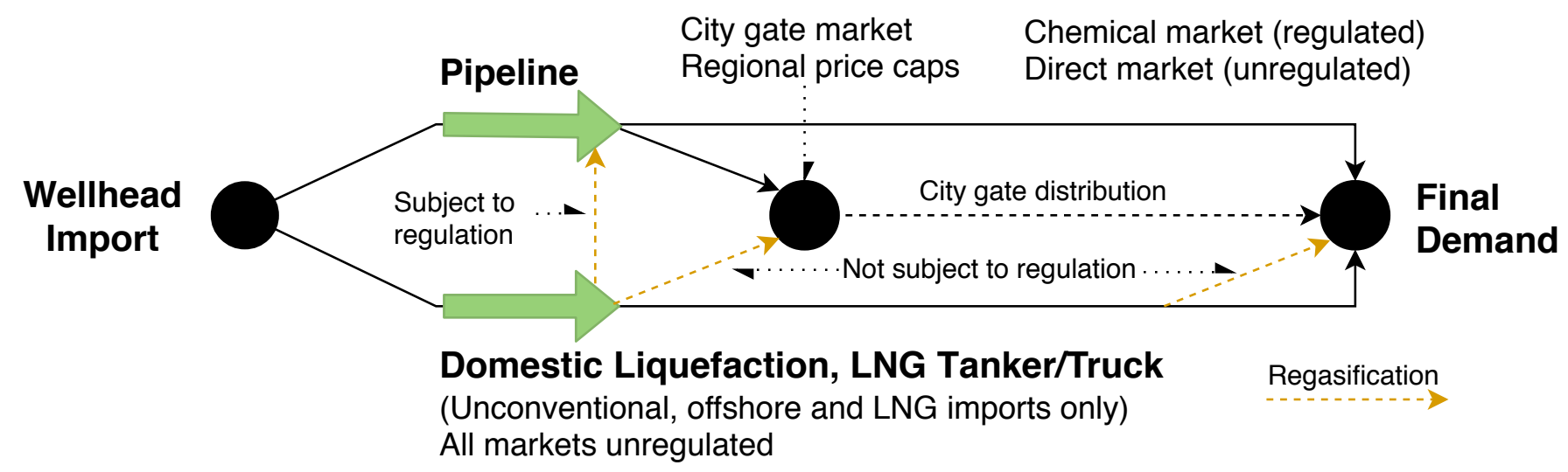

Figure 2. Supply pathways for domestic and imported gas.

Source: KAPSARC research.

\section{Transportation pathways and infrastructure}

Figure 2 shows the possible supply pathways and associated regulations for onshore and pipeline imports, offshore and unconventional (shale, CBM, CMM), and LNG supplies represented in the model. The market is segmented into different regional consumer groups that are exposed to different pricing policies: unregulated consumer prices for direct consumers, capped prices labeled as city gate, and the regulated chemical industry.

In the first case, natural gas - either produced onshore or imported via pipeline - is sent by pipeline to meet demand from large industries and smaller residential and non-residential consumers beyond the city gate. Gas prices are capped for the chemical industry and at the city gate and deregulated for large industrial consumers and direct users.

Unconventional and offshore natural gas supplies have similar pathways. They can be sent via pipelines, or via LNG tanker or truck, which involves liquefaction and regasification. The supply pathways for imported LNG are similar: 1) re-gasified and sent via pipelines to meet direct, city gate or chemical demand; 2) sent as LNG via trucks to meet demand in all markets (bypassing the price caps).

We use the average transportation cost for a pipeline with a diameter of 40 inches as a standard cost for inter-provincial pipeline transportation: $\$ 0.002103$ per kcm-km (QS 2016). We estimate the LNG ground transportation cost using data provided by ICIS (2016): $\$ 0.0118$ per kcm-km. Pipeline imports are priced at $\$ 285$ per $\mathrm{kcm}$ along the western border of China with Central Asia. Pipeline imports under contract from Central Asia are set to $33.7 \mathrm{bcm}$ as a lower bound, allowing for additional imports if economical. LNG imports are priced at $397 \mathrm{USD} / \mathrm{bcm}$ in all coastal provinces.

Tracking upstream and midstream infrastructure ownership by the NOCs (Figure 1b) allows us to introduce different TPA scenarios. In one case, firms can deliver gas to provinces utilizing only their own infrastructure. In another scenario, we assume equal access to capacity for all suppliers. This could be achieved through strict enforcement with more competitive pipeline tariffs, the introduction of an independent operator, or the FERC open access rules under order 636 (FERC). Companies lacking access to pipelines due to access restrictions or capacity constraints can deliver gas as LNG to consumers in neighboring provinces. 


\section{Analysis and Discussion}

\section{Establishing the baseline}

The baseline scenario reflects the condition of the Chinese natural gas supply market in 2015, including suppliers producing, delivering and importing natural gas (both LNG and pipeline gas) at observed levels. Price caps are imposed for pipeline gas supplied to the city gate and chemical markets, with corresponding contractual obligations required by the large NOCs. Direct consumers are not subject to price caps and LNG supplies are unregulated. Firms organize to minimize the aggregate supply costs, while also minimizing the regional market penalties associated with delivering supplies at capped prices. The latter is achieved by prioritizing unregulated delivery modes, in this case LNG, beyond the contractual obligations. We also introduce restricted pipeline access to reflect conditions in 2015: the NOCs limited access to their inter-provincial pipelines.

Table 2 compares the results of the baseline scenario with the supply patterns of the Chinese gas market in 2015. The national average of the marginal supply costs, representing wholesale prices, are reported in $\$ / \mathrm{kcm}$. In Figure 3 we map the provincial marginal supply costs in the baseline and other counterfactual scenarios described below. Table A2-2 in Appendix 2 lists the actual marginal costs generated in each scenario.

The marginal costs are very high in the base case, as companies have to incur the extra costs of liquefaction in order to have deregulated prices. In Figure 4 we map the percentage difference between the spot and city gate prices, showing that the regional price caps are binding for most provinces (positive values). On average, across all provinces, the difference exceeds the caps by 17 percent in the baseline. Certain western inland provinces, on the other hand, incur significant - more than 25 percent - price distortions. These distortions have a significant impact not only on the marginal costs but also on the choices of supply sources and transportation options, total costs and overall efficiency of the upstream gas market.

Table 2. Production, imports, marginal supply and total costs in each scenario.

\begin{tabular}{l|l|l|l|l|l} 
Source & $\mathbf{2 0 1 5}$ data & Baseline & $\begin{array}{l}\text { No price } \\
\text { caps }\end{array}$ & $\begin{array}{l}\text { Price caps } \\
\text { with TPA }\end{array}$ & $\begin{array}{l}\text { No price caps } \\
\text { with TPA }\end{array}$ \\
\hline Domestic production, bcm & 135 & 136 & 136 & 136 & 136 \\
\hline Domestic liquefaction, bcm & 10.0 & 9.58 & 0.82 & 9.58 & 0.64 \\
\hline Pipeline imports, bcm & 34.2 & 34.9 & 36.2 & 43.4 & 47.1 \\
\hline LNG imports, bcm & 27.2 & 27.6 & 24.8 & 19.8 & 14.9 \\
\hline Total supply, bcm & 197 & 198 & 197 & 199 & 198 \\
\hline Pipeline shipment, bcm-km & N/A & 243,776 & 234,291 & 280,044 & 286,910 \\
\hline LNG shipment, bcm-km & N/A & 10,850 & 993 & 9,634 & 844 \\
\hline $\begin{array}{l}\text { Average of marginal supply } \\
\text { costs, \$/kcm }\end{array}$ & N/A & 419 & 357 & 419 & 353 \\
\hline Change from baseline, \% & N/A & - & $-14 \%$ & $0 \%$ & $-16 \%$ \\
\hline Total cost, \$ million & - & 28,908 & 27,554 & 28,195 & 26,725 \\
\hline Saving, $\%$ & & & $4.7 \%$ & $2.5 \%$ & $7.6 \%$ \\
\hline Net saving, \$ million & & - & 1,354 & 713 & 2,183
\end{tabular}

Source: 2015 data from CEIC and ICIS (domestic liquefaction), KAPSARC research (scenarios). 


\section{Lifting the price caps}

Figures 3(b) and 4(b) represent a market where the price caps are lifted assuming the demand remains unchanged, but access to pipelines is still restricted. That is, the firms coordinate to satisfy demand, without enforcing obligations or prioritizing more expensive unregulated delivery pathways. In this and all other scenarios, available infrastructure and production capacity remain the same as the baseline, and we allow freedom in

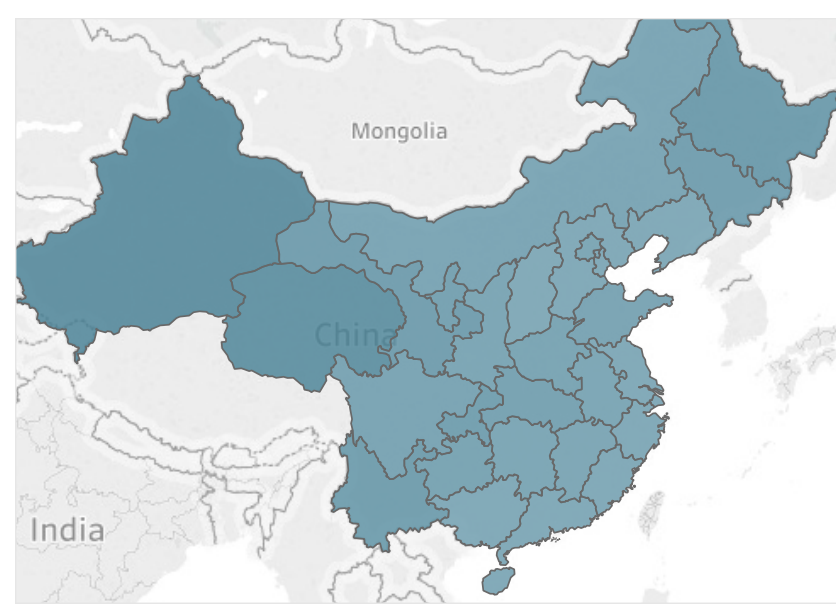

A. Baseline

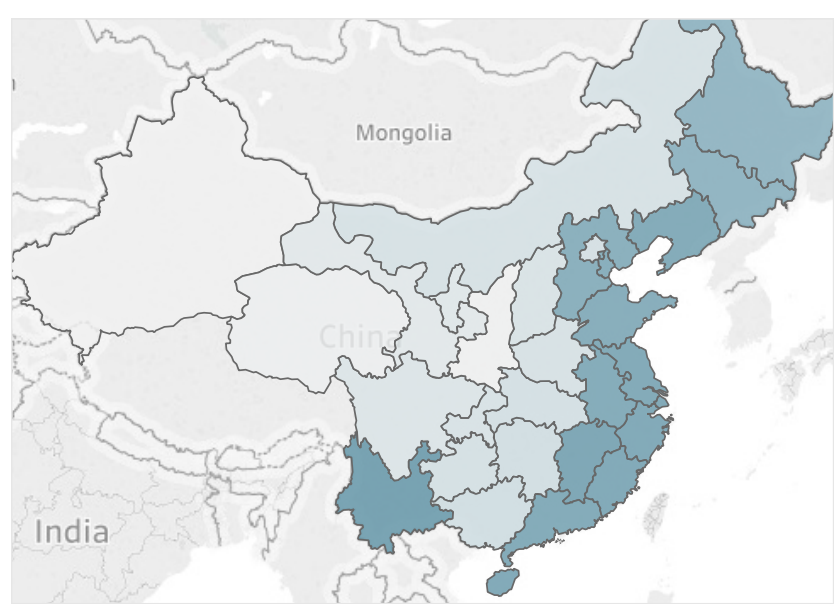

C. No price caps how import sources are selected, beyond existing pipeline contracts.

We compare the 'no price caps' scenario, the baseline and 2015 statistics in Table 2. Key model indicators include total production, domestic liquefaction, pipeline and LNG imports, average marginal cost (weighted by provincial demand), and total systems cost. On average, spot prices (marginal supply costs) decrease by 14 percent from $\$ 419 / \mathrm{kcm}$ or $\$ 10.6 /$ one million British

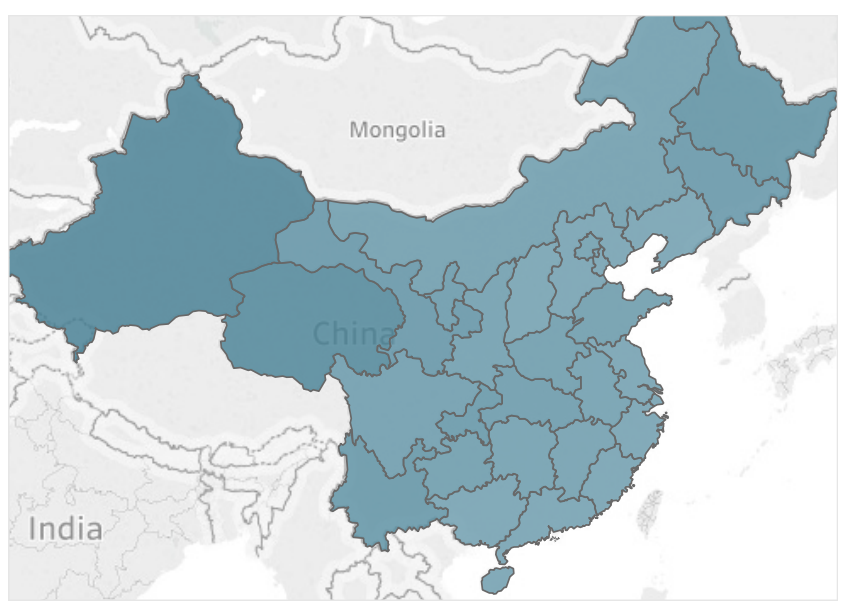

B. Price caps with TPA

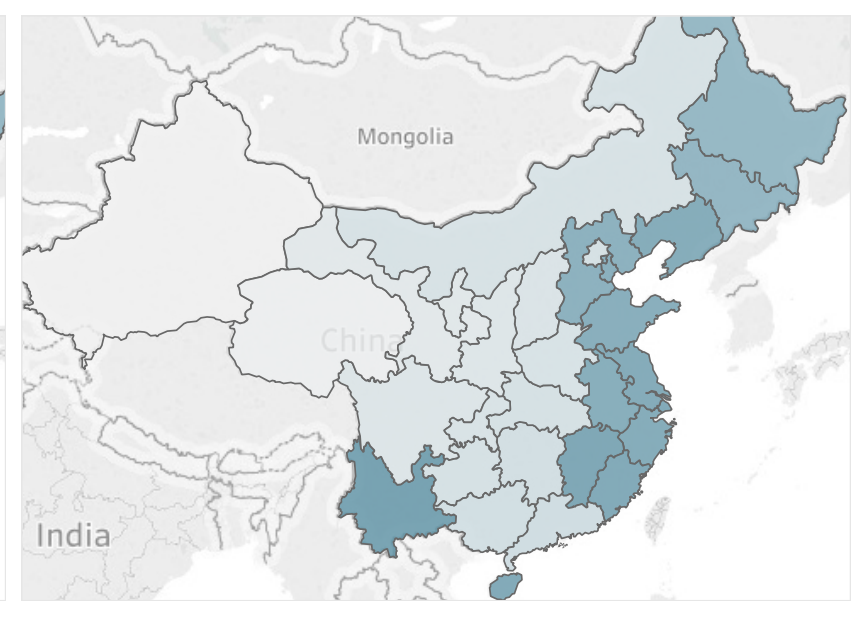

D. No price caps with TPA

\section{Marginal cost, $\$ / \mathbf{k c m}$}

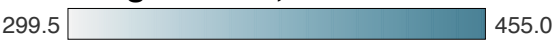

Figure 3. Provincial marginal supply costs (spot prices) or opportunity costs (regulated market) in four scenarios, $\$ / \mathrm{kcm}$. Source: KAPSARC research. 
thermal units (MMBtu) to $\$ 357 / \mathrm{kcm}$ (\$9.7/MMBtu) when lifting the price caps, as liquefaction and trucking is no longer a necessary step to deliver unregulated natural gas. Total systems costs are reduced by 4.7 percent, or $\$ 1.4$ billion.

Domestic liquefaction and LNG movements by tanker truck decrease by more than 90 percent. Pipeline shipments are also optimized, with a 3.7 percent increase in less expensive pipeline

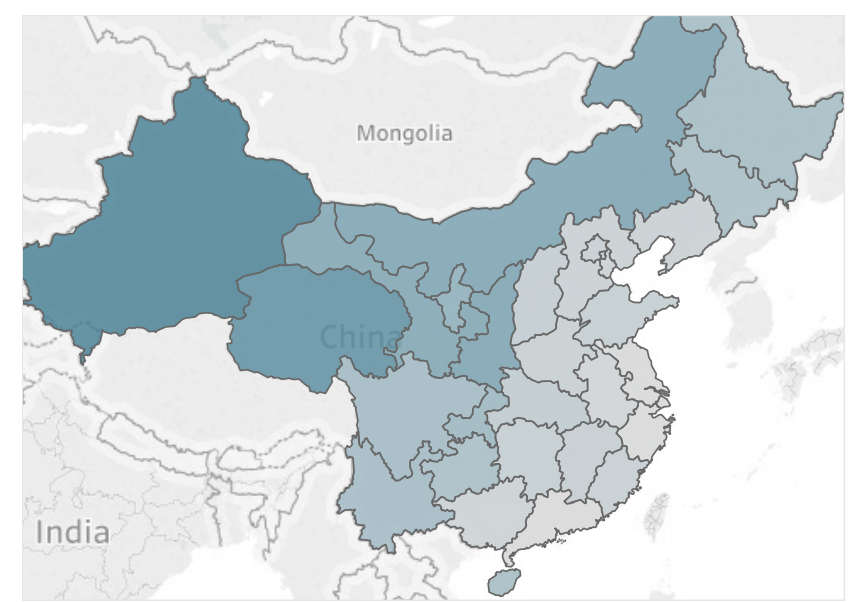

\section{A. Baseline}

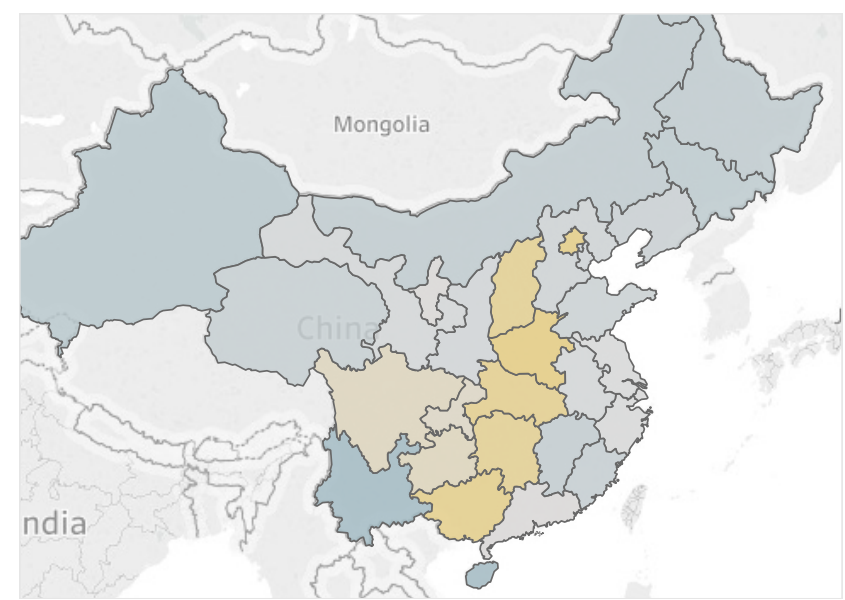

C. No price caps imports. The combination of increased imports from Central Asia, and injecting into pipelines what would have been trucked as LNG, leads to the substantially increased pipeline utilization shown in Table 2. Note that in many provinces in the 'no price caps' scenarios marginal costs fall below the price caps at the city gate (Figure 4), which means the effect of the regulations is actually to increase the price above the caps in many regions.

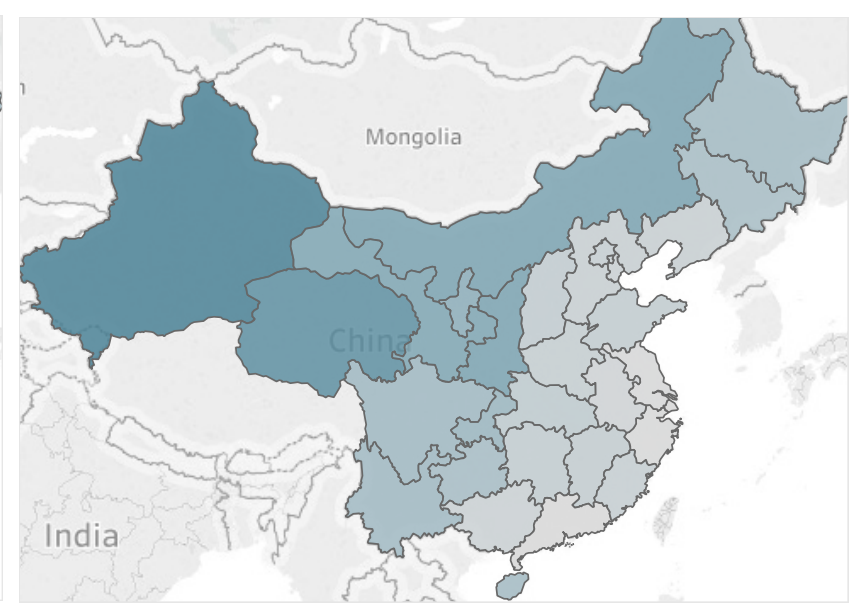

B. Price caps with TPA

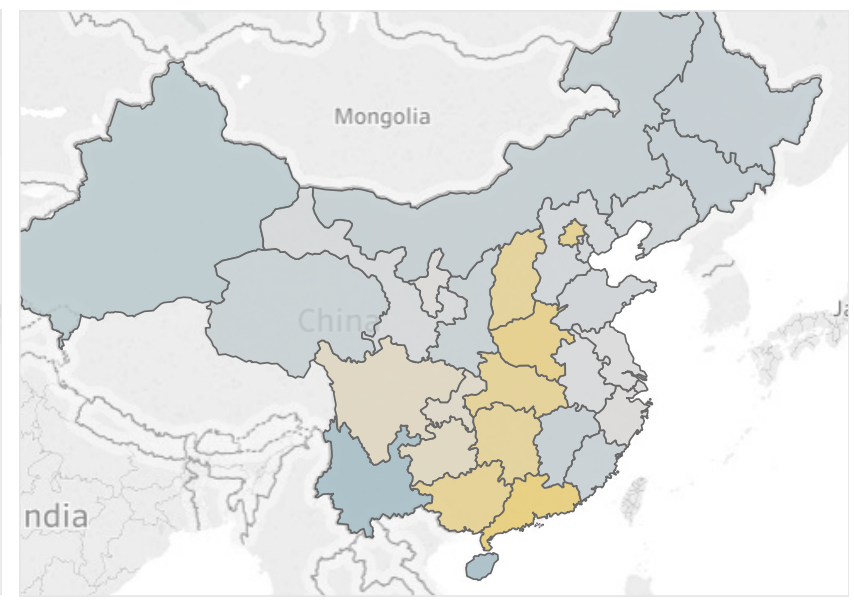

D. No price caps with TPA

\section{$\%$ Difference \\ $-20.08$ 73.09}

Figure 4. Difference between marginal cost and city gate price caps.

Source: KAPSARC research. 


\section{The role of the TPA reform}

Next, we introduce two additional scenarios in which the TPA policy is reformed, providing all market players with fair access to provincial pipelines and regasification capacity. First, we assess the impact of TPA under the price controls, 'price caps with TPA,' then - in a market without price caps, 'no price caps with TPA.' The results of these scenarios are included in Table 2, Figures 3 and 4.

In the 'price caps with TPA' scenario we observe a significant decline (28 percent) in LNG imports, nearly 3 times the decline in the 'no price caps' scenario (10 percent). This suggests that restricted access to pipeline capacity at the provincial level plays a significant role in driving import choices. However, the savings in import costs are offset by the firms prioritizing domestic liquefaction and LNG deliveries under the caps, resulting in a lower cost saving (2.5 percent). We also observe no significant impact on marginal supply costs.

The benefit of combining price reform with TPA increases substantially over implementing just TPA. In the scenario - 'no price caps with TPA' - the overall economic gain increases to 7.6 percent, or $\$ 2.2$ billion. We see a further shift from LNG to Central Asian pipeline imports and a large drop in domestic liquefaction and LNG shipments. Therefore, improving provincial pipeline access and removing the incentives for the domestic LNG market can lead to a much more efficient use of transnational capacity for imported pipeline gas.

When we optimize the short-run supply logistics, we consider only the operating costs, which represent a fraction of the West-East pipeline tariff, and treat existing capacity as a sunk investment. Pipeline tariffs charged by the CNPC along the West-East pipeline, reach as high as $\$ 4 / \mathrm{MMBtu}(\$ 112 / \mathrm{kcm})$
(OIES 2014). The tariffs are designed to cover a regulated rate of return on pipeline investments by the NOCs, which represents the major share of the total cost. Given a pipeline import price of $\$ 285 / \mathrm{kcm}$ in 2015 , the total cost of delivering the imported gas across $4000 \mathrm{~km}$, roughly the length of the pipeline from China's western border to Shanghai, is $\$ 397 / \mathrm{kcm}$. At this cost, pipeline imports would be uncompetitive with coastal LNG imports (priced at $\$ 379 / \mathrm{kcm}$ in 2015), and marginally competitive with LNG shipped to inland consumers near the coast.

To determine if the provincial marginal costs (prices) in the 'no price caps' scenarios (Table A3-2) are sufficient to recover CNPC's transnational pipeline investment, we calculate an annualized cost of moving imported gas across the West-East pipeline. We derive an annualized capital cost of $\$ 46.8 / \mathrm{kcm}$ based on a total investment of $\$ 14.5$ billion (IHS Edin) for $17 \mathrm{bcm}$ of annual capacity, assuming a 50-year lifetime and a 5 percent discount rate. Combined with the pipeline operating cost estimate $(\$ 0.0021 /$ $\mathrm{kcm}-\mathrm{km})$, we find a total cost of $\$ 55 / \mathrm{kcm}$ (\$2/MMBtu). Including the pipeline import price, the total delivery cost is $\$ 340 / \mathrm{kcm}$; well below the LNG import prices in coastal provinces and within the range of the equilibrium prices of several inland provinces.

Given that our estimated annualized transportation cost (investment and operation) is well below $\$ 4 / \mathrm{MMBtu}$, the transnational pipeline tariff is more representative of the opportunity cost of substituting coastal LNG imports than of a regulated cost-plus rate of return. Thus, existing pipeline tariffs can represent a major barrier to reforming national pipeline access for third-party suppliers if the infrastructure remains on the NOCs' balance sheet. Transporting their own supplies at cost, they would be able to lock out competitors with the current tariff structure. 
Given the regional structure of natural gas supply and demand, there is clear potential for China to benefit from an integrated national gas market, with better access and competition between participating firms.

\section{Implications for market participants}

Our analysis carries significant insights for market players. Under the 'no price cap' scenarios, domestic liquefaction almost disappears. Given that smaller independent producers resort to liquefaction, their market share will shrink, especially if they do not get access to pipelines due to regulatory failure and the location of their assets.

Unless there is a major shift in the price relationship between imported pipeline gas and LNG, CNOOC, as the dominant LNG importer, would be under the most pressure from both lifting the price caps and effective pipeline access reform, including more competitive tariffs. Independent importers would still have a market for their LNG spot purchases to supply coastal provinces (if such purchases remain cheaper than existing long-term contracts).

Removing the supply incentives for unregulated LNG deliveries leads to declines in the domestic LNG market as a whole. Without the price caps there is no incentive for domestic liquefaction and LNG deliveries, as suppliers can seek out higher rents from unregulated pipeline deliveries. As a result, gas-fueled transportation industries located inland may encounter elevated competition for previously protected domestic sources of LNG from coastal LNG imports. Other gas-consuming industries, which are not dependent on LNG, would benefit.

The TPA reform can have a significant impact on pipeline shipments, and lifting the price caps can further expand this impact. Under the 'TPA and no caps' scenario, pipeline gas shipments by independent producers via existing capacity increase by more than 80 percent. CNPC, as a pipeline import monopolist, is also well positioned to take advantage of more competitive pipeline imports following these policy reforms, and would still dominate the midstream sector given that the pipeline infrastructure is not divested into a separate entity. However, the potential increase in domestic pipeline shipments will rely heavily on establishing a pipeline tariff system based on actual costs.

In the scenarios with no price caps, the provincial marginal supply costs (spot prices) fall well below $(>20 \%)$ the city gate price caps in several inland provinces (Figure 4), and on average do not exceed the caps by more than 1 percent. In the market with caps, we see that the spot prices for gas, dominated by LNG deliveries, exceed the price caps across the country, creating a significant discrepancy between the prices for incremental demand and the contractual obligations for pipeline deliveries. Lifting the price caps would equalize prices without posing a significant disadvantage to market segments under the previously regulated pipeline prices, and support more competitive spot prices for existing and new consumers in serval inland provinces. 
W e assess the economic distortions caused by regulated prices in China's natural gas supply market and estimate the potential economic gains from improved supplier coordination. Price caps incentivize rational profitmaximizing firms to deliver LNG at unregulated prices, increasing total costs. In combination with restricted TPA, this results in a suboptimal use of the existing domestic pipeline infrastructure.

Our study demonstrates the benefits of the holistic approach to modeling energy markets. Having a detailed regional representation of supply and demand integrated via cross-regional midstream infrastructure, based on the 2015 data, enables us to pinpoint the responses of the local markets to strategic national policies. It also helps identify market-wide issues, such as the competition dynamics of the pipeline gas imports from Central Asia arriving from the north-western border, and LNG imports landing in eastern coastal provinces. Our unique representation of the market as an MCP also offers a methodological contribution to the study of energy markets with regulated prices, building on the work of Murphy et al. (2016). The demand-side impacts associated with reforming China's natural gas prices is an area of future research.

Our 'no price caps' scenario demonstrates how existing regulation favors domestic LNG operations and higher LNG imports. CNOOC, as a dominant LNG importer, could come under pressure in case of price reform. Independent importers would still have a market for their LNG spot purchases to supply coastal provinces (if such purchases remain cheaper than existing long-term contracts). Domestic liquefaction activities by independent producers with limited access to the inter-provincial pipeline network would be at a disadvantage.

Open access to China's midstream infrastructure is an issue at both the provincial level and for local distribution networks within each province. In response, the government continued to roll out reforms to improve the market in 2016 and 2017. This is in line with our analysis suggesting that resolving TPA restrictions, including structural reforms, efficient enforcement and affordable tariffs, supports greater use of existing transnational pipeline network, the integration of China's regional gas markets, and economic imports from Central Asia. However, without addressing the incentive created by the government-enforced price caps, profit-maximizing firms will continue to prioritize unregulated LNG supplies.

Improving both TPA and removing the incentives created by the price caps in 2015 could have generated costs savings of 7.6 percent ( $\$ 2.2$ billion) for China's natural gas sector. Our analysis shows how rationalizing pipeline prices can contribute to cost savings by replacing domestic liquefaction and LNG imports with more economical supplies. Marginal supply costs averaged across the country decline by 16 percent and fall below the government-enforced price caps in several central provinces, which would improve the cost competitiveness of natural gas and support China's future growth targets.

In highly concentrated markets, such as the Chinese natural gas upstream and midstream sectors, the dominant players can undermine the implementation of reform initiatives if such reforms counter their interests. Even if such initiatives eventually materialize, the NOCs can mute the potential efficiency gains from market liberalization through exercising their market power in a deregulated market. In this regard, representation of the ownership structure of supply, and capturing the market power (where applicable) in the model formulation, could be a potential direction for further research. 
Another potential research direction could cover the effects of distorted price signals beyond the direct economic costs. For example, the impact of unequal profit distribution in the industrial value chain on investment (or lack of thereof) in the higher-risk upstream sector. On the opposite end of the supply chain, current policies support excessive channels of gas distribution and sales that can drive up consumer prices and lead to excessive profits for distributors at retail levels beyond the city gate. Eliminating artificial price differentials across consumer types and geographies would reduce the incentives to deliver more expensive gas (e.g., unregulated LNG), thereby decreasing price inflation across China. Initiatives to rationalize wholesale prices for all gas supplies, such as the ongoing pilot program in Fujian province and recent reforms in the chemical fertilizer industry, support such efforts. 
Aolin, Hu, Dong Qing. 2015. "On natural gas pricing reform in China." Natural Gas Industry B 2(4): 374-382.

Chen, Jiaru. 2016. "Analysis of China's Oil and Gas Policy in 2015." China Oil and Gas 1: 8-15.

China Daily. 2015. "PetroChina offers incentives." August 7, 2015. Accessed March 2018. http://www.chinadaily. com.cn/business/2015-08/07/content 21524654.htm

China Daily. 2017. "China to improve pricing mechanism in urban gas distribution." June 23, 2017. Accessed March 2018. http://www.chinadaily.com.cn/ business/2017-06/23/content 29858419.htm

China Daily. 2017. "China to push for reform on oil and gas pipeline operations". September 5, 2017. Accessed March 2018. http://www.chinadaily.com.cn/china/201709/05/content 31594643.htm

Ministry of Land and Resources, People's Republic of China. 2015. China Mineral Resources Report 2015. Beijing: Geological Publishing House. Accessed February 2018. http://www.mlr.gov.cn/sjpd/ zybg/2015/201510/P020151030354926948039.pdf

Fang, Xiangliang, Fangjing Ma. 2017. "Right Time, Uncertain Direction for Natural Gas Reform." Caixing Global, May 21. Accessed February 2018. https://www. caixinglobal.com/2017-05-21/101093121.html

Federal Energy Regulatory Commission (FERC). "Order No. 636 - Restructuring of Pipeline Services". Accessed February 2018. https://www.ferc.gov/legal/maj-ord-reg/ land-docs/restruct.asp

He, Jiang, Chen Jianrong, C. 2017. "Analysis of China's Oil and Gas Policies in 2016". China Oil \& Gas: Policies and Law 24 (1): 3-9. CNPC Economic \& Technology Research Institute.

Hu, Desheng, Shengqing Xu. 2013. "Opportunity, challenges and policy choices for China on the development of shale gas". Energy policy 60: 21-26 https://doi.org/10.1016/j.enpol.2013.04.068
ICIS. 2017. "China's LNG truck transportation faces oversupply, low crude". Sun Xuelian, published 10 April 2015. Accessed February 2018. https://www.icis.com/ resources/news/2015/04/10/9873410/china-s-Ing-trucktransportation-faces-oversupply-low-crude/

IHS EDIN. "A web-based solution that provides your fastest, easiest access to our most current E\&P", Basin and Midstream content. Accessed February 2018. https://cdn.ihs.com/www/pdf/EDIN-Upstream-English.pdf

IHS Vantage. https://ihsmarkit.com/products/vantage.html

IHS QUE\$TOR. https://www.ihs.com/products/questoroil-gas-project-cost-estimation-software.html

Interfax Global Energy. 2016. "China's NOCs drag feet on third-party access", 24 May 2017, Tang Tian. Accessed February 2018. http:// interfaxenergy.com/gasdaily/article/26043/ chinas-nocs-drag-feet-on-third-party-access

The Lantau Group (TLG). 2014. "The Devil Down Below: Developing China's Shale Gas". September 2014. Accessed February 2018. http://www.lantaugroup.com/ files/tlgchina gas sep14.pdf

Li, Xin. 2015. "Natural gas in China: a regional analysis", Oxford Institute for Energy Studies. Accessed February 2018. https://www.oxfordenergy.org/wpcms/wp-content/ uploads/2015/11/NG-103.pdf

Lowe, Philip, Ingrida Pucinskaite, William Webster, Patrick Lindberg. 2007. "Effective unbundling of energy transmission networks: lessons from the Energy Sector Inquiry". Competition Policy Newsletter 1: 23-34. Accessed March 2018. http://ec.europa.eu/competition/ publications/cpn/2007 1 23.pdf

MacAvoy, Paul. 1970, "The effectiveness of the Federal Power Commission", The Bell Journal of Economics and Management Science 1 (2): 271-303.

http://www.jstor.org/stable/3003184

DOI: $10.2307 / 3003184$ 
Matar, Walid, Frederic Murphy, Axel Pierru, and Bertrand Rioux. 2017. "Efficient industrial energy use: The first step in transitioning Saudi Arabia's energy mix". Energy Policy 105: 80-92. http://doi.org/10.1016/j.enpol.2017.02.029

Matar, Walid, Frederic Murphy, Axel Pierru, and Bertrand Rioux. 2015. "Lowering Saudi Arabia's fuel consumption and energy system costs without increasing end consumer prices". Energy Economics 49: 558-569. https://doi.org/10.1016/j.eneco.2015.03.019

Mu, Fuyuan, Weizhi Zhong, Xianliang Zhao, Changbo Che, Yanpeng Chen, Jie Zhu, Bo Wang. 2015.

"Strategies for the development of CBM gas industry in China". Natural Gas Industry B 2 (4): 383-389.

https://doi.org/10.1016/j.ngib.2015.09.013

Murphy, Frederic, Axel Pierru, Yves Smeers. 2016. "A Tutorial on Building Policy Models as MixedComplementarity Problems". Interfaces 46 (6): 465-481 https://doi.org/10.1287/inte.2016.0842

National Development and Reform Commission of China (NDRC). 2014. "Measures for the construction and operation of natural gas infrastructure". Accessed February 2018. http://www.gov.cn/foot/ site1/20140320/001e3741a2cc149493b001.pdf

NDRC. 2015. "Notice on rationalizing non-residential natural gas price (2015/351)". Accessed February 2018. http://www.ndrc.gov.cn/zcfb/zcfbtz/201502/ $\underline{\mathrm{t} 20150228 \text { 665694.html }}$

NDRC. 2016. "13th Five-Year Plan for Natural Gas Development”. Accessed February 2018. https://policy. asiapacificenergy.org/sites/default/files/\%E5\%A4\%A9\%E 7\%84\%B6\%E6\%B0\%94\%E5\%8F\%91\%E5\%B1\%95\%E2 $\% 80 \% 9$ C $\%$ E5\%8D\%81\%E4\%B8\%89\%E4\%BA\%94\%E2 \%80\%9D\%E8\%A7\%84\%E5\%88\%92.pdf

NDRC. 2017. "Energy Supply and Consumption Revolution Strategy (2016-2030)". Accessed February 2018. http://www.ndrc.gov.cn/gzdt/201704/ t20170425 845304.html
National Energy Administration of China (NEA), 2014. "Measures for Supervision of Opening up Oil and Gas Pipeline Facilities in a Fair Manner". Accessed February 2018. http://www.nea.gov.cn/2014-02/24/c 133139014.htm

Oxford Institute for Energy Studies (OES). 2014. "The Development of Chinese Gas Pricing: Drivers, Challenges and Implications for Demand". July 2014. ISBN: 978-1-78467-007-8.

Paltsev Sergey, Danwei Zhang. 2015. "Natural gas pricing reform in China: Getting closer to a market system?" Energy policy 86: 43-56.

Reuters, 2016, "China's flurry of gas measures to lift investment, third-party access". November 16. Accessed March 2018. https://www.reuters.com/article/us-chinagas-reform/chinas-flurry-of-gas-measures-to-liftinvestment-third-party-access-idUSKBN13B0D3

Rioux, Bertrand, Galkin Philipp, Frederic Murphy, Axel Pierru. 2016. "How do Price Caps in China's Electricity Sector Impact the Economics of Coal, Power and Wind? Potential Gains from Reforms". The Energy Journal 38: 63-75. https://doi.org/10.5547/01956574.38.SI1.brio

Rioux, Bertrand, Galkin Philipp, Frederic Murphy, Axel Pierru (2016), "Economic impacts of debottlenecking congestion in the Chinese coal supply chain". Energy Economics 60: 387-399. http://doi.org/10.1016/j. eneco.2016.10.013

Shell International and Development and Research Center. 2017. "China's Gas Development Strategies. Advances in Oil and Gas Exploration and Production". Accessed February 2018. https://link.springer.com/book/ 10.1007\%2F978-3-319-59734-8

SIA. 2015. "Two Steps Forward, One Step Back: 2015 China Non-residential Gas Pricing Reform". SIA Commentary, 28 February 2015.

SIA. 2017. SIA China Energy Weekly, Week 1 Jan 2nd 8th, 2017. 
Trusted Sources. 2016. "Third-party access under pressure from China's big three oil companies" 12 July 2016. Accessed February 2018. http://www. trustedsources.co.uk/blogs/energy/third-party-accessunder-pressure-from-china-s-big-three-oil-companies

Wang, Jianling, Lianyong Feng, Lin Zhao, Simon Snowden. 2013. "China's natural gas: Resources, production and its impacts". Energy Policy 55: 690-698. https://doi.org/10.1016/j.enpol.2012.12.034

Wang, Suling, Jiange Li. 2014. "Research of the effect of the monopoly of China natural gas industry in shale gas development and the corresponding countermeasures". Journal of Chemical and Pharmaceutical Research 6(4):504-508.

Xu, Jing, Michelle Hallack, Miguel Vazquez. 2017. "Applying a third-party access model for China's gas pipeline network: an independent pipeline operator and congestion rent transfer". Journal of Regulatory Economics 51 (1): 72-29. https://doi.org/10.1007/s11149-017-9316-z
Yong, Qin, Ye Jianping. 2015. "A Review on Development of CBM Industry in China". Search and Discovery Article \#80454. Accessed Febraury 2018. http://www.searchanddiscovery.com/pdfz/ documents/2015/80454yong/ndx yong.pdf.html

Zhang, Wei, Jun Yang, Zongyi Zhang, Joshua D. Shackman. 2017. "Natural gas price effects in China based on the CGE model". Journal of Cleaner Production 146: 497-505. https://doi.org/10.1016/j.jclepro.2017.01.109

Zhang, Qi, Zhan Li, Ge Wang, Hailong Li. 2015. "Study on the impacts of natural gas supply cost on gas flow and infrastructure deployment in China", Applied Energy 162: 1385-1398. https://doi.org/10.1016/j.apenergy.2015.06.058 


\section{Appendix 1: Model Formulation}

\section{Sets}

$r, r^{\prime} \quad$ Model regions

$i, j \quad$ Suppliers operating in the gas market

$g$ Production or field type (conventional, unconventional, offshore, CBM, CMM, associated)

$m \quad$ Market segment (chemical, city gate, direct)

w Gas state for use in pipeline (pipe) or as $L N G$

$s \quad$ Supply steps representing assets in each supply region

\section{Variables}

$d_{i m r w}$ Natural gas distributed in market $m$ and region $r$ in state $w$ by supplier $i$

$\delta_{m r w}$ Obligations to deliver gas type $w$ in market $m$ and region $r$ when a price cap is binding

$t_{i j r^{\prime} w}$ Transportation (pipeline/LNG) by firm $i$ on infrastructure owned by firm $j$ from $r$ to $r$ '

imp $_{\text {irw }}$ Quantity of gas imported by firm $i$, in region $r$, in state $w$ (pipeline or LNG)

$l_{i r} \quad$ Unloading of LNG by firm $i$ for regasification, and injection into pipeline or delivery to consumer

$q_{i g r s w}$ Natural gas production by firm $i$, from field type $g$, in $r$, from $s$, and in state $w$ (pipeline or LNG)

$p_{r} \quad$ Marginal supply cost (competitive market price) in each region

\section{Dual variables}

$\pi_{m r}$ Dual on the total gas supplied to each regional market; Eq. (2.3) $\eta_{m r w}$ Dual on the distribution of contractual obligations between suppliers; Eq. (2.4)

$\mu_{i g r s}$ Dual on the production constraint for production type $g$, asset $s$, owned by firm $i$; Eq. (2.5)

$\sigma_{i r} \quad$ Dual on the firm's liquefaction capacity constraint; Eq. (2.6)

$\lambda_{i r w}$ Dual on the firm's supply balance constraint; Eq. (2.7)

$\gamma_{i r r^{\prime} w}$ Dual on the firm's transportation capacity constraint from region $r$ to $r^{\prime}$ by type $w$; Eq. (2.8)

$v_{i w} \quad$ Dual on the firm's import contract constraint; Eq. (2.9)

$\xi_{\text {ir }} \quad$ Dual on the firm's regasification capacity constraint; Eq. (2.10)

\section{Cost coefficients and other parameters}

$C P_{\text {igrsw }} \quad$ Marginal cost of production and processing of gas by firm $i$ for type $g$ in region $r$ and state $w$

$C T_{r r^{\prime} w} \quad$ Variable transportation cost from $r$ to $r$ ' for gas type $w$

$C R \quad$ Marginal regasification cost

$D_{m r} \quad$ Fixed gas demand in market $m$ and region $r$

$D L_{m r w} \quad$ Supply obligations associated with the price cap for gas delivered to each regional market

$E_{\text {igrs }} \quad$ Existing production capacity by firm $i$, for gas type $w$, in region $r$, and suppply step $s$ 
$F_{i r r^{\prime} w} \quad$ Existing transportation capacity owned by firm $i$ from region $\mathrm{r}$ to $\mathrm{r}^{\prime}$ for gas type $w$

$G_{i r} \quad$ Existing liquefaction capacity owned by firm $i$ in region $r$

$H_{i r} \quad$ Regasification capacity owned by firm $i$ in region $r$

$I_{r w} \quad$ Import price in region $r$ by type $w$

$L^{i n j} \quad$ Liquefaction losses

$L^{\text {reg }} \quad$ Regasification losses

$L_{r r^{\prime} w}^{t r} \quad$ Transportation losses

$\hat{P}_{m r w} \quad$ Price cap in market $m$ and region $r$ for gas in state $w$

\section{Regulated market conditions}

First, we introduce a set of equations that describes the impact created by the price caps for each regional market and delivery mode, $\hat{p}_{m r w}$. We introduce $p r$ as the market price in region $r$. Equation (1.1) defines the variable $z_{m r w}$ as the potential lost revenue for a cubic meter of gas for suppliers if they deliver gas at a price cap below the market price. It is stated as a maximum value as it should be zero when the market clears below the cap. This expression is linearized by re-defining $z_{m r w}$ as a slack variable in (1.2). We introduce the non-negative variable $\delta_{m r w}$, orthogonal to constraint (1.2), representing government-enforced delivery obligations when the price cap is binding for a given type of gas (pipeline or LNG). Constraint (1.3) sets the enforced contractual obligations to the actual levels in the market, the coefficient $D L_{m r w}$. We assume that a market for trading obligations exists, ensuring their efficient distribution between firms.

$$
\begin{array}{ll}
z_{m r w}=\max \left(p_{r}-\hat{p}_{m r w}, 0\right) & \\
z_{m r w} \geq p_{r}-\hat{p}_{m r w} & \perp \delta_{m r w} \geq 0 \\
D L_{m r w}-\delta_{m r w} \geq 0 & \perp i m r w
\end{array}
$$

Let's consider the two possible outcomes for the complementarity pairs in (1.2) and (1.3). When the market price is below the price cap,

$$
p_{r}<\hat{p}_{m r w}: z_{m r w}=0, \delta_{m r w}=0
$$

there is no need for the government to enforce contractual obligations, as the market clears at a price below the cap, and $\delta_{m r w}=0<D L_{m r w^{*}}$ In the second case, the price cap is binding,

$$
p_{r}>\hat{p}_{m r w}: z_{m r w}=p_{r}-\hat{p}_{m r w}, \delta_{m r w}>0
$$

Now the government needs to enforce the pricing policy, requiring physical delivery of gas at the capped price, and (1.3) enforces that the subsidized gas meets the demand $\delta_{m r w}=D L_{m r w}$. The limit case, where the market clearing price equals the price cap, represents the situation when the government needs to start enforcing the obligations.

\section{The suppliers' optimization problem}

Next, we introduce the suppliers' optimization problem in (2) as an adjusted total system cost minimization expressed in a complementarity format. The problem is then transformed into an MCP and solved numerically using the General Algebraic Modeling System (GAMS) and the PATH solver.

The objective function, equation (2.1), consists of two terms: the aggregate firm costs, $k_{i}$ defined in 
(2.2), plus the total lost revenues from selling at the price caps $\sum_{i m r w} d_{i m r w} z_{m r w}$.

Natural Gas Supply Problem

$$
\begin{aligned}
& \min \sum_{i} k_{i}+\sum_{i m w} d_{i m r w} z_{m r w} \\
& k_{i}=\sum_{g r s w} C_{i g r s w} q_{i g r s w}+\sum_{r r^{\prime}}\left(\sum_{w} \sum_{j} C T_{r r^{\prime} w} t_{j i r r^{\prime} w}\right) \\
& +\sum_{i w w} I_{r v} i m p_{i w w}+\sum_{i r} C R \cdot l_{i r} \quad \forall i \\
& \sum_{i w} d_{i w w} \geq D_{m r} \quad \perp \pi_{m r} \geq 0 \quad \forall r \\
& \sum_{i} d_{i m r w} \geq \delta_{m r w} \quad \perp \eta_{m r w} \geq 0 \quad \forall m r w \\
& \sum_{w} q_{i g r s w} \leq E_{i g r s} \quad \perp \mu_{i g r s} \geq 0 \quad \forall i g r s \\
& \sum_{g} \sum_{s} \sum_{w=L N G} q_{i g r s w} \leq G_{i r} \quad \perp \sigma_{i r} \geq 0 \quad \forall i \\
& \perp \lambda_{i w w} \geq 0 \quad \forall i r, w=p i p e
\end{aligned}
$$

$$
\begin{aligned}
& \sum_{g} \sum_{s} q_{i g r s w}+i m p_{i w w}+l_{i r}\left(1-L^{r e g}\right)+\sum_{j} \sum_{r^{\prime}} t_{i j r^{\prime} r w}\left(1-L_{r^{\prime} w}^{r r}\right) \geq \sum_{j} \sum_{r^{\prime}} t_{j i r r^{\prime} w}+\sum_{m} d_{i m w w} \\
& \perp \lambda_{i i v} \geq 0 \quad \forall i r, w=L N G
\end{aligned}
$$

$\sum_{g} \sum_{s} q_{i g r s w}\left(1-L^{i q}\right)+i m p_{i m w}+\sum_{j} \sum_{r^{\prime}} t_{i r^{\prime} r^{\prime} w}\left(1-L_{r r^{\prime} w}^{t r}\right) \geq l_{i r}+\sum_{j} \sum_{r^{\prime}} t_{j i r^{\prime} w}+\sum_{m} d_{i n n w}$ $\sum_{j} t_{j i r r^{\prime} w} \leq F_{i r r^{\prime} w} \quad \perp \gamma_{i r r^{\prime} w} \geq 0 \quad \forall i r r^{\prime} w$

$$
\begin{array}{lll}
\sum_{r} \text { imp }_{i r w} \geq \text { Contracts }_{i w} & \perp v_{i w} \geq 0 & \forall i w \\
l_{i r} \leq H_{i r} & \perp \zeta_{i r} \geq 0 & \forall i w
\end{array}
$$

$$
q_{i g r s w} \geq 0, t_{i j r r^{\prime} w} \geq 0, i m p_{i r w} \geq 0, l_{i r} \geq 0, d_{i m r w} \geq 0
$$

The costs include the total cost of production and liquefaction, $\sum_{\text {grsw }} C_{\text {igrsw }} q_{\text {igrsw }}$, transportation costs for both pipeline and LNG, $\sum_{w j r r^{\prime}} C T_{r r^{\prime} w} t_{j i r r^{\prime} w}$, natural gas import cost via pipeline and LNG, $\sum_{i r w} I_{i r w} i m p_{i r w}$, and regasification costs, $\sum_{i r} l_{i r} C R$.
The problem is subject to the remaining logistical constraints. Next to each constraint we also introduce the corresponding orthogonal dual variables.

Equation (2.3) is the fixed demand constraint for each region and market segment. It provides the standard condition that the marginal supply cost $\pi_{r w}$, the dual variable on the constraint, is zero if the suppliers deliver an excess supply of gas. Constraint (2.4) enforces that the aggregate deliveries from the firms satisfy the contractual obligations, efficiently allocating them between each company. Its dual variable $\eta_{m r w}$ represents the marginal value of the trade of the government's supply obligations.

Equation (2.5) is the upstream production constraints assuming a fixed capacity for each firm's regional assets, $E_{\text {igrs }}$. Equation (2.6) is the regional constraint on liquefaction capacity for each firm. Equation (2.7a) and (2.7b) are the supply balances for gas distributed by pipeline and LNG, respectively. For pipelines, the sum of gas produced, imported, entering by pipeline and LNG injected $\left(l_{i r}\right)$ into the network exceeds the gas distributed to all markets minus the gas sent out by pipeline. The same applies for LNG, except the term $l_{i r}$, is moved to the right-hand side of the inequality as an LNG sink. The dual variable on these constraints, $\lambda i r w$, represents the marginal value of supplying gas by each delivery mode.

The constraint ensures efficient allocation of the obligations between firms. The transportation capacity constraint for shipment by pipe and LNG is defined in equation (2.8), with the coefficient $F_{i r r^{\prime} w}$ describing existing network capacity. Equation (2.9) defines existing long-term import contracts, used primarily for pipeline purchases agreements.

\section{The KKT conditions}

Now we derive the Karush-Kuhn-Tucker conditions that describe the equilibrium of the natural gas 
market. The resulting MCP captures the cost of the market distortion created by the capped prices.

Equation (3) shows the Lagrangian of the supplier's optimization problem.

$\forall i$

$L=-\sum_{g r s w} C_{i g r s w} q_{i g r s w}-\sum_{r r^{\prime}}\left(\sum_{w} \sum_{j} t_{j i r r^{\prime} w} C T_{r r^{\prime} w}\right)-\sum_{i r w} I_{r w} i m p_{i r w}-\sum_{i r} l_{i r} C R$

$-\sum_{i m w} d_{i m r w} z_{i m r w}+\sum_{i g r s w} q_{i g r s w} \underline{\mu}_{i g r s w}+\sum_{m r v} d_{i m r v} \underline{\lambda}_{i m r v}+\sum_{m r v} l_{i r} \underline{\zeta}_{i r}$

$+\sum_{m} \sum_{r}\left(\sum_{i w} d_{i m r w}-D_{m r}\right) \pi_{m r}+\sum_{m} \sum_{r} \sum_{w}\left(\sum_{i} d_{i m r w}-\delta_{m r w}\right) \eta_{m r w}$

$+\sum_{g} \sum_{r} \sum_{s}\left(E_{i g r s}-\sum_{w} q_{i g r s w}\right) \mu_{i g r s}+\sum_{r} \sum_{r^{\prime}} \sum_{a}\left(F_{i r r^{\prime}}-\sum_{j} t_{j i r r^{\prime} w}\right) \gamma_{i r r^{\prime} w}$

$+\sum_{i} \sum_{r} \sum_{w}\left(\begin{array}{c}\sum_{g} \sum_{s} q_{i g r s w}\left(1-L_{L N G(w)}^{i n j}\right)+i m p_{i r w}+l_{i r, g a s(w)}\left(1-L^{r e g}\right) \\ +\sum_{j} \sum_{r^{\prime}} t_{i j r^{\prime} r w}\left(1-L_{r r^{\prime} w}^{t r}\right)-l_{i r, L N G(w)}-\sum_{j} \sum_{r^{\prime}} t_{i j r r^{\prime} w}-\sum_{m} d_{i m r w}\end{array}\right) \lambda_{i r w}$

$+\sum_{i} \sum_{w}\left(\sum_{r}\right.$ imp $_{i r w}-$ Contracts $\left._{i w}\right) \eta_{i w}+\sum_{i} \sum_{r}\left(H_{i r}-l_{i r}\right) \zeta_{i r}$

Equations (3.1) to (3.5) come from imposing the condition that the gradient of the Lagrangian with respect to the partial derivatives of $q_{i g r s w}, i m p_{i r w}, t_{i j r r^{\prime} w^{\prime}}$, $l_{i r}$ and $d_{i m r w}$, respectively, equals to zero in the optimal solution, as it should be a stationary point.

$$
\begin{array}{llll}
0 \geq-C_{i g r s w}-\mu_{i g r s}+\sum_{m} \lambda_{i m r v}+\sigma_{i r, w=L N G} & \perp & q_{i g r s w} \geq 0 & \forall i r s \\
0 \geq-I_{r w w}+\sum_{m} \lambda_{i m r w}+v_{i w} & \perp & \text { imp }_{i r w} \geq 0 & \forall i r w
\end{array}
$$

(3)

$$
0 \geq-\gamma_{j r r^{\prime} w}+\lambda_{i r^{\prime} w}-\lambda_{i r w} \quad \perp \quad t_{i j r r^{\prime} w} \geq 0 \quad \forall i j r r^{\prime} w
$$

$$
0 \geq-C R+\lambda_{i r, p i p e(w)}\left(1-L^{r e g}\right)-\lambda_{i r L N G(w)} \quad \perp \quad l_{i r} \geq 0 \quad \forall i r
$$

$$
0 \geq \pi_{m r}-z_{m r v}-\lambda_{i r w}+\eta_{m r w} \quad \perp \quad d_{i m r w} \geq 0 \quad \forall i m r w
$$

Next, we include the original primal constraints (2.3) to (2.10). To complete the MCP describing the supply market with regulated prices we include the market conditions (1.3) and (1.4), and connect them to the supplier's problem by requiring the unregulated market price, $p r$, to be greater than the regional marginal supply costs from all market segment, $\pi_{m r}$, in equation (4).

$p_{r} \geq \pi_{m r} \quad \perp \quad \xi_{m r} \geq 0 \quad \forall m r$ 


\section{Appendix 2: Marginal Supply Costs by Province}

Table A2-1. Provincial demand by market segment for the year 2015 in bcm.

\begin{tabular}{|c|c|c|c|c|}
\hline Province & Chemical & City gate & Direct & Total \\
\hline Anhui & & 2.66 & 0.66 & 3.3 \\
\hline Beijing & & 6.79 & 6.79 & 13.6 \\
\hline Chongqing & 3.26 & 2.55 & 5.81 & 11.6 \\
\hline Fujian & & 3.48 & 0.87 & 4.3 \\
\hline Gansu & 0.43 & 1.90 & 0.58 & 2.9 \\
\hline Guangdong & 0.03 & 5.28 & 5.31 & 10.6 \\
\hline Guangxi & & 0.62 & 0.15 & 0.8 \\
\hline Guizhou & 0.12 & 0.99 & 0.28 & 1.4 \\
\hline Hainan & 0.02 & 4.07 & 4.10 & 8.2 \\
\hline Hebei & 0.16 & 3.29 & 3.45 & 6.9 \\
\hline Heilongjiang & & 2.79 & 0.70 & 3.5 \\
\hline Henan & 0.36 & 3.43 & 3.79 & 7.6 \\
\hline Hubei & 0.07 & 2.90 & 0.74 & 3.7 \\
\hline Hunan & & 1.96 & 0.49 & 2.5 \\
\hline Inner Mongolia & 0.53 & 2.75 & 0.82 & 4.1 \\
\hline Jiangsu & 0.14 & 7.62 & 7.76 & 15.5 \\
\hline Jiangxi & & 1.28 & 0.32 & 1.6 \\
\hline Jilin & 0.03 & 1.61 & 0.41 & 2.1 \\
\hline Liaoning & 0.44 & 2.32 & 2.76 & 5.5 \\
\hline Ningxia & 0.26 & 1.50 & 0.44 & 2.2 \\
\hline Qinghai & 1.04 & 2.74 & 1.00 & 4.8 \\
\hline Shaanxi & 0.05 & 3.91 & 3.95 & 7.9 \\
\hline Shandong & & 3.85 & 3.85 & 7.7 \\
\hline Shanghai & & 3.51 & 3.51 & 7.0 \\
\hline Shanxi & 0.02 & 3.09 & 3.12 & 6.2 \\
\hline Sichuan & 3.15 & 5.91 & 9.06 & 18.1 \\
\hline Tianjin & 0.14 & 2.92 & 3.07 & 6.1 \\
\hline Xinjiang & & 6.96 & 6.96 & 13.9 \\
\hline Yunnan & & 0.47 & 0.12 & 0.6 \\
\hline Zhejiang & 0.02 & 3.73 & 3.75 & 7.5 \\
\hline
\end{tabular}

Source: CEIC 2017 and KAPSARC analysis. 
Table A2-2. Provincial marginal supply costs under the modeling scenarios.

$\begin{array}{lllll}\text { Province } & \text { Baseline, } \$ / \mathrm{kcm} & \begin{array}{l}\text { No price caps, } \\ \$ / \mathrm{kcm}\end{array} & \begin{array}{l}\text { Price caps with } \\ \text { TPA, } \$ / \mathrm{kcm}\end{array} & \begin{array}{l}\text { No price caps } \\ \text { with TPA, } \$ / \mathrm{kcm}\end{array}\end{array}$

\begin{tabular}{|c|c|c|c|c|c|}
\hline Anhui & 415 & 406 & 415 & 403 & 3.3 \\
\hline Beijing & 415 & 322 & 415 & 322 & 13.6 \\
\hline Chongqing & 426 & 319 & 426 & 319 & 11.6 \\
\hline Fujian & 410 & 410 & 410 & 410 & 4.3 \\
\hline Gansu & 428 & 311 & 428 & 311 & 2.9 \\
\hline Guangdong & 410 & 408 & 410 & 327 & 10.6 \\
\hline Guangxi & 410 & 326 & 410 & 326 & 0.8 \\
\hline Guizhou & 419 & 322 & 419 & 322 & 1.4 \\
\hline Hainan & 410 & 410 & 410 & 410 & 8.2 \\
\hline Hebei & 410 & 399 & 410 & 397 & 6.9 \\
\hline Heilongjiang & 433 & 388 & 433 & 386 & 3.5 \\
\hline Henan & 418 & 320 & 418 & 320 & 7.6 \\
\hline Hubei & 422 & 323 & 422 & 322 & 3.7 \\
\hline Hunan & 415 & 325 & 415 & 325 & 2.5 \\
\hline Inner Mongolia & 417 & 321 & 417 & 320 & 4.1 \\
\hline Jiangsu & 410 & 409 & 410 & 407 & 15.5 \\
\hline Jiangxi & 414 & 414 & 414 & 414 & 1.6 \\
\hline Jilin & 427 & 391 & 427 & 389 & 2.1 \\
\hline Liaoning & 410 & 408 & 410 & 406 & 5.5 \\
\hline Ningxia & 423 & 313 & 423 & 312 & 2.2 \\
\hline Qinghai & 449 & 302 & 449 & 302 & 4.8 \\
\hline Shaanxi & 416 & 300 & 416 & 315 & 7.9 \\
\hline Shandong & 418 & 403 & 418 & 402 & 7.7 \\
\hline Shanghai & 410 & 410 & 410 & 410 & 7.0 \\
\hline Shanxi & 409 & 318 & 409 & 318 & 6.2 \\
\hline Sichuan & 418 & 316 & 418 & 316 & 18.1 \\
\hline Tianjin & 410 & 402 & 410 & 400 & 6.1 \\
\hline Xinjiang & 455 & 300 & 455 & 300 & 13.9 \\
\hline Yunnan & 429 & 425 & 429 & 425 & 0.6 \\
\hline Zhejiang & 410 & 410 & 410 & 406 & 7.5 \\
\hline
\end{tabular}

Source: KAPSARC research. 


\section{Appendix 3: Evaluation of Production and Costs}

B elow is a description of the methodology used to construct the cost analysis for production of different gas types and for midstream infrastructure.

For the purpose of this study, we split Chinese gas supply into seven types:

Natural gas onshore

Natural gas offshore

Shale gas

Associated gas

Coal-bed methane (CBM)

Coal-mine methane (CMM)

Synthetic natural gas (SNG)

For each type of gas, we estimated capital costs (CAPEX), operating costs (OPEX), and decommissioning (decom) cost per million standard cubic meters ( $\mathrm{mscm}$ ), and identified production levels maximum potential production per year - the plateau rate. Where necessary, we scaled the costs to the 2015 level - the calibration year for the KEM China gas model - applying the IHS capital and operational cost indices.

The supply costs were estimated as follows:

Total cost $\$ / \mathrm{mscm}=\$$ CAPEX $+\$$ OPEX $+\$$ Decom, where:

CAPEX $(\$ / \mathrm{mscm})=$ Total $\$$ CAPEX/Rec. reservesBcm

OPEX $(\$ / \mathrm{mscm}=$ OPEXperY\$ * YearsProd/ Cum.ProductionBcm
Decom $(\$ / \mathrm{mscm})=\$$ DecomTotal $/$ Rec .

reservesBcm

For each asset a maximum rate of production plateau rate per year - was estimated from its production profile:

Plateau rate bcm/year = MAX (2015Prod:

EndProduction)

\section{Natural gas: onshore and offshore}

There are 270 onshore and 40 offshore gas assets in the IHS Vantage database. Table A3-1 shows the breakdown of the average CAPEX, OPEX and decom costs, as well as the plateau rate statistics from the database. Figure A3-1 represents the aggregated natural gas production profile.

\section{Shale gas}

We used the IHS Vantage database, which contains 20 shale gas assets, for the cost and production data. The aggregated cost and production data is presented in the Table A3-2 and Figure A3-2.

\section{Associated gas}

IHS Vantage estimate that 311 oil assets will produce $341 \mathrm{bcm}$ of associated gas until 2104. Most of China's oilfields that produce associated gas are at the mature stage with declining gas production.

The costs for associated gas are considered to be a part of the oil field project costs. Therefore, we are not taking into account any cost data related to associated gas for our model. Table A3-3 and Figure A3-3 present the production data for associated gas. 
Table A3-1. Production data for onshore and offshore assets.

\begin{tabular}{|c|c|c|c|c|c|c|c|c|c|c|c|c|}
\hline \multirow[t]{2}{*}{ Gas Type } & \multicolumn{3}{|c|}{ CAPEX, \$/mscm } & \multicolumn{3}{|c|}{ OPEX, \$/mscm } & \multicolumn{3}{|c|}{ Decom, \$/mscm } & \multicolumn{3}{|c|}{$\begin{array}{l}\text { Max plateau rate } \\
\text { bcm/year }\end{array}$} \\
\hline & MAX & AVG & MIN & MAX & AVG & MIN & MAX & AVG & MIN & MAX & AVG & MIN \\
\hline $\begin{array}{l}\text { Natural gas } \\
\text { Onshore }\end{array}$ & 171.2 & 13.4 & 0 & 521.0 & 45.0 & 0 & 43.0 & 1.6 & 0 & 19.4 & 0.7 & 0 \\
\hline $\begin{array}{l}\text { Natural gas } \\
\text { Offshore }\end{array}$ & 269.4 & 70.2 & 0 & 232.6 & 111.4 & 11.3 & 93.3 & 15.9 & 0.3 & 3.7 & 0.8 & 0.1 \\
\hline
\end{tabular}

Source: IHS Vantage.

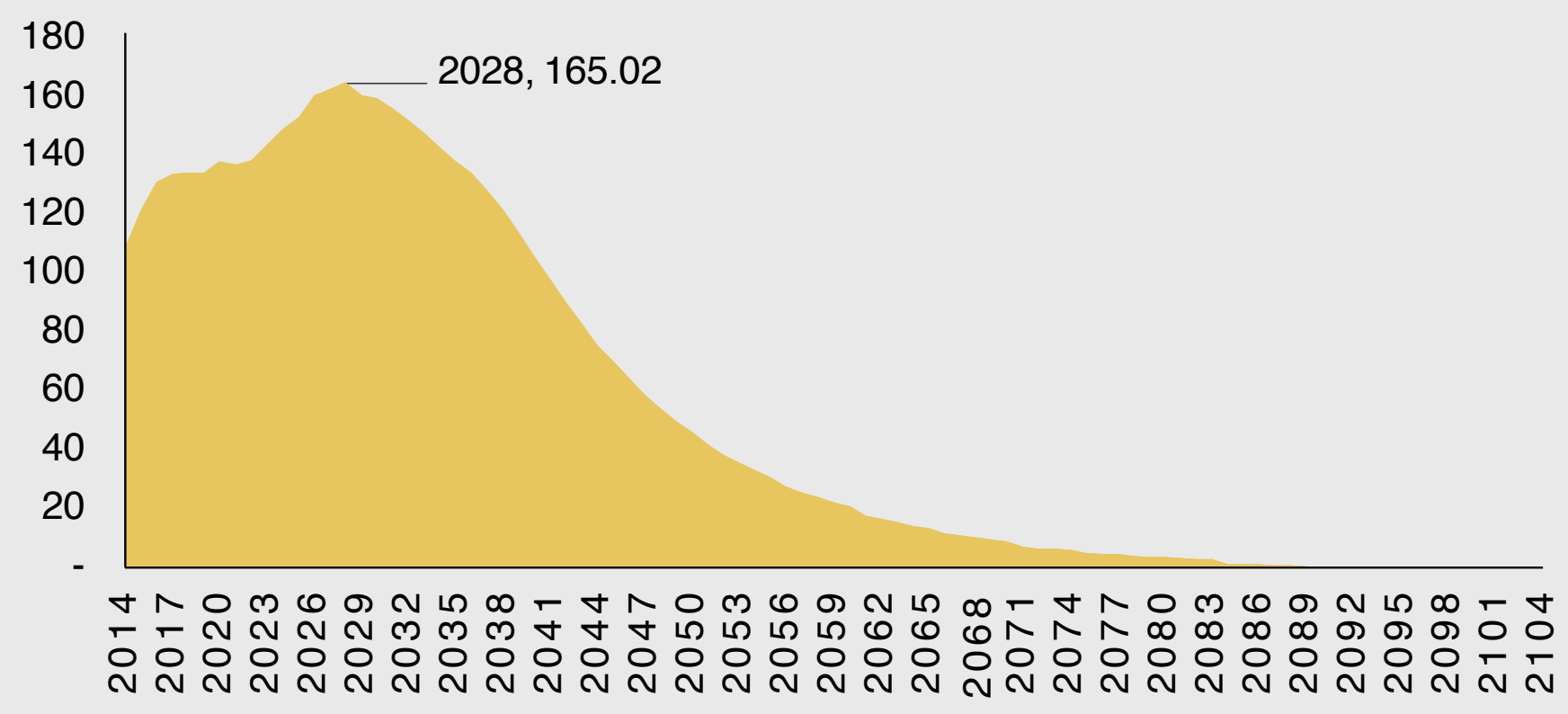

Figure A3-1. China's natural gas production profile, bcm.

Source: IHS Vantage. 
Table A3-2. Production data for shale gas assets.

\begin{tabular}{|c|c|c|c|c|c|c|c|c|c|c|c|c|}
\hline \multirow[t]{2}{*}{ Gas Type } & \multicolumn{3}{|c|}{ CAPEX, $\$ / \mathrm{mscm}$} & \multicolumn{3}{|c|}{ OPEX, \$/mscm } & \multicolumn{3}{|c|}{ Decom, $\$ / \mathrm{mscm}$} & \multicolumn{3}{|c|}{$\begin{array}{l}\text { Max plateau rate } \\
\text { bcm/year }\end{array}$} \\
\hline & MAX & AVG & MIN & MAX & AVG & MIN & MAX & AVG & MIN & MAX & AVG & MIN \\
\hline Shale gas & 304.6 & 184.4 & 5.4 & 109.3 & 63.6 & 45.0 & 4.8 & 3.1 & 1.3 & 8.5 & 3.6 & 2.0 \\
\hline
\end{tabular}

Source: IHS Vantage.

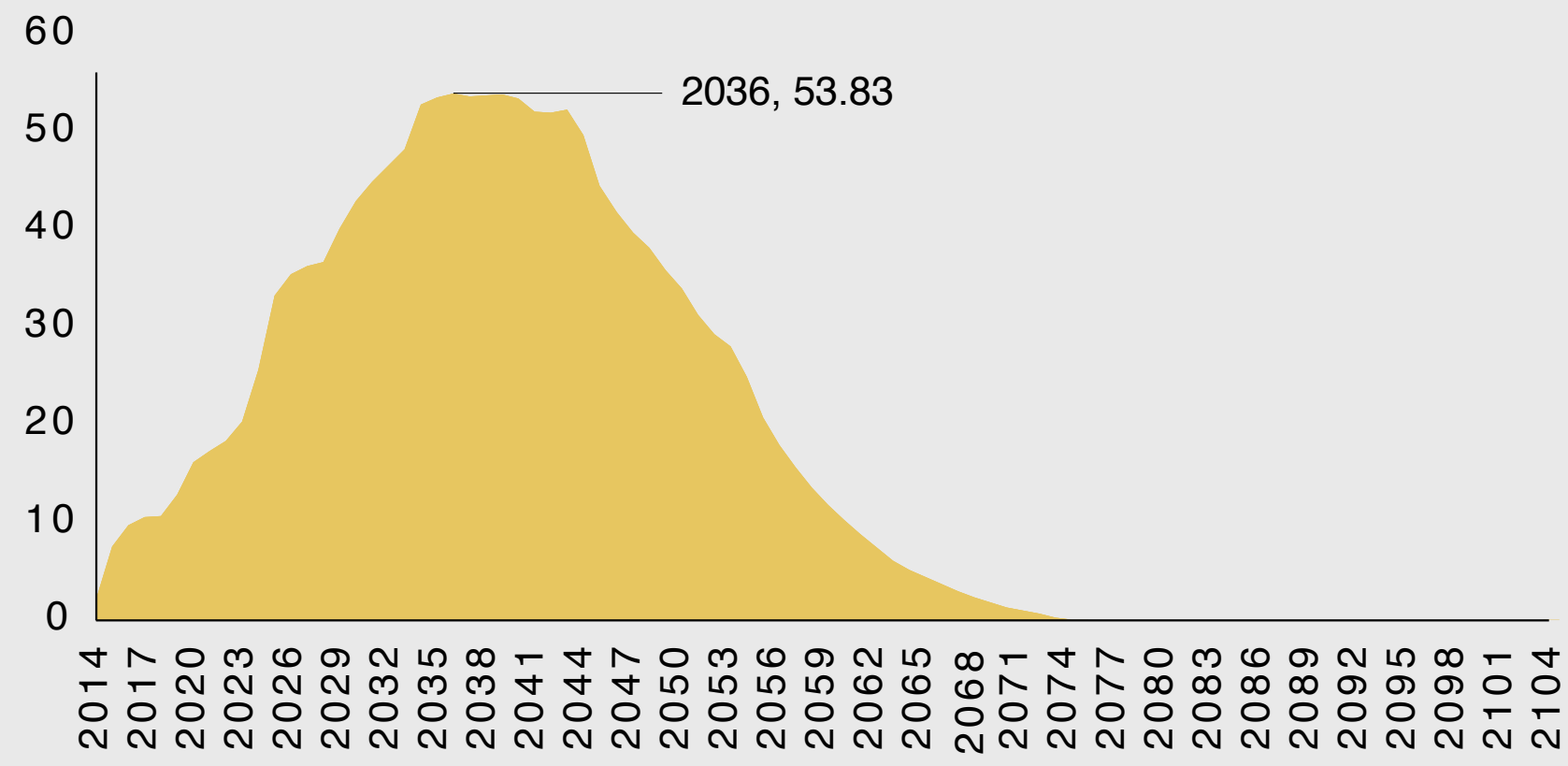

Figure A3-2. China's shale gas production profile, bcm.

Source: IHS Vantage. 
Table A3-3. Production data for associated gas.

\begin{tabular}{l|l|l|l} 
Gas type & \multicolumn{2}{|l}{ Max plateau rate, bcm/year } & \\
\cline { 2 - 4 } & MAX & AVG & MIN \\
\hline Associated gas & 1.3 & 0.08 & 0
\end{tabular}

Source: IHS Vantage. 


\section{Coal-bed methane (CBM)}

CBM is a methane gas trapped in the coal plays; an unconventional form of natural gas found in coal deposits or coal seams. Historically, it was vented to the atmosphere to reduce hazards during the coal mining process, but later the drilling and production techniques of the oil and gas industry were employed initially to extract methane from coal. However, significant differences in the coal bed reservoir properties, gas storage mechanisms, the gas-transport phenomenon, resource decline rates, and water disposal have required innovations and changes to the conventional procedures. The lack of asset-specific production data for CBM required us to use the archetype project for plateau generation and cost estimation.

We used several data sources (MLR 2015; Qin and Ye 2015; Mu et al. 2015) to obtain the data on CBM production, reserves, and characteristics of major basins. Taking into account the data on geological resources, recoverable resources and geological reserves, and applying an approximate 30 percent recovery rate, we obtained around 188 billion cubic meters of recoverable CBM gas for China.

We then estimated the recoverable resources for specific producing regions using the following formula:

Estimated recoverable reserves, bcm $=(R p /$ Rptotal * 100) * Rr/100, where:

Rp - Predicted producing resources by basin

Rptotal - Total predicted producing resources

$$
\mathrm{Rr} \text { - Recoverable reserves for China (188 bcm) }
$$

Table A3-4 shows the resulting distribution data.

Table A3-4. Distribution and characteristics of major CBM blocks.

\begin{tabular}{|c|c|c|c|c|c|c|}
\hline Block play & Basin & Depth, m & $\begin{array}{l}\text { CBM } \\
\text { resources } \\
10 * 8 \mathrm{~m} 3\end{array}$ & $\begin{array}{l}\text { Predicted } \\
\text { proved } \\
\text { resources } \\
10 \star 8 \mathrm{~m} 3\end{array}$ & $\begin{array}{l}\text { Predicted } \\
\text { producing } \\
\text { resources } \\
10 \star 8 \mathrm{~m} 3\end{array}$ & $\begin{array}{l}\text { Estimated } \\
\text { recoverable } \\
\text { resources, } \\
\text { bcm }\end{array}$ \\
\hline \multicolumn{7}{|l|}{ Class I } \\
\hline $\begin{array}{l}\text { Southern Qinshui } \\
\text { Basin }\end{array}$ & Qinshui & $200-1200$ & 8900 & 6230 & 3730 & 22.7 \\
\hline Eastern Ordos Basin & Ordos & $300-1500$ & 11485 & 7440 & 4310 & 26.2 \\
\hline Yangquan-Heshun & Liupansui & $300-1000$ & 6448 & 4190 & 2430 & 14.8 \\
\hline Gulin, Xuyong & Liupansui & $300-1200$ & 1000 & 650 & 370 & 2.2 \\
\hline $\begin{array}{l}\text { Yinggangling in } \\
\text { Pingle }\end{array}$ & Ningwu & $800-1500$ & 214 & 130 & 70 & 0.4 \\
\hline \multicolumn{7}{|l|}{ Class II } \\
\hline Huolinhe & Erlian & $150-1500$ & 1025 & 660 & 360 & 2.2 \\
\hline $\begin{array}{l}\text { Xixiagou in } \\
\text { Santanghu Basin }\end{array}$ & Tuha & $600-1500$ & 2170 & 1300 & 680 & 4.1 \\
\hline Southern Tarim & Tarim & $300-1500$ & 15700 & 9420 & 4990 & 30.3 \\
\hline Yili & Tianshan & $500-1500$ & 5912 & 3540 & 1870 & 11.4 \\
\hline Wushenqi & Ordos & $300-1500$ & 17000 & 11050 & 6070 & 36.9 \\
\hline Changji-Fukang & Junggar & $800-1200$ & 5600 & 3640 & 2000 & 12.2 \\
\hline
\end{tabular}




\begin{tabular}{|c|c|c|c|c|c|c|}
\hline \multicolumn{7}{|l|}{ Class III } \\
\hline $\begin{array}{l}\text { Huangling-Binxian } \\
\text { Changwu }\end{array}$ & Ordos & $300-1500$ & 1435 & 780 & 370 & 2.2 \\
\hline Huhehu & Erlian & $600-1500$ & 1325 & 720 & 340 & 2.1 \\
\hline Boli & $\begin{array}{l}\text { Sanjiang } \\
\text { Muleng }\end{array}$ & $500-1500$ & 3100 & 1700 & 850 & 5.2 \\
\hline Jixi-Hegang & $\begin{array}{l}\text { Sanjiang } \\
\text { Muleng }\end{array}$ & $350-1500$ & 1533 & 840 & 400 & 2.4 \\
\hline Panguan & Liupansui & $800-1200$ & 1900 & 1040 & 490 & 3.0 \\
\hline Hengshanbao & Ningwu & $400-1500$ & 2203 & 1210 & 580 & 3.5 \\
\hline Shenmu & Ordos & $500-1500$ & 2281 & 1250 & 600 & 3.6 \\
\hline Southern Ningwu & Ningwu & $300-1500$ & 1665 & 910 & 430 & 2.6 \\
\hline Total & & & 90896 & 56700 & 30940 & 188 \\
\hline
\end{tabular}

Sources: Ministry of Land and Resources of the People's Republic of China, Qin and Ye 2015, Mu et al. 2015, KAPSARC research.

The CBM extraction process has many similarities with the development of gas from conventional reservoirs. However, significant differences between reservoirs have a great impact on profitability and operations. A coal play can be extensive by size and spread over a large territory, so it requires drilling a large number of wells, water supply for further fracking and gathering a system of pipelines. In China, the development of unconventional reservoirs is complicated because of the rough terrain, complex geology and other factors.

We studied several existing CBM projects in China. Based on their parameters, we created a representative average project. The CBM project archetype was developed using IHS QUE\$TOR software: a cost engineering tool for greenfield development concepts and cost assessment. Table A3-5 lists the resulting primary project parameters.

Having specified the project parameters, we created a development concept (see Figure A3-4) including:

63 horizontal wells.
62 vertical wells.

Gas gathering and treatment station.

Field and transportation pipeline to the local liquefaction station.

After selecting a concept and adjusting the parameters of production wells, we built a production profile - shown in Figure A3-5.

After the project archetype was completed and adjusted, we were able to estimate a project cost in current dollars and discount it to the calibration year by applying the CAPEX and OPEX indices provided by IHS. We adjusted the costs by the amount of subsidy (0.2 RMB/m3) that CBM producers received according to the Chinese policy. Table A3-6 presents the resulting cost estimations.

\section{Coal-mine methane (CMM)}

CMM is a natural gas, mostly consisting of methane, located in working coal mines associated with coal deposits. During the exploitation of coal mines, a 
lot of methane is released into the atmosphere as a direct result of the physical process. Methane should be removed from mine tunnels using special ventilation systems to prevent hazards or explosions. CMM is primarily utilized near the mine - in local liquefaction plants or generation sites.
We estimate the CMM output and utilization volumes based on the levels recorded in recent years (see Table A3-7 for details). The CMM extraction cost is assumed to be a part of coal mine development expenditures.

\section{Gas gathering}

station

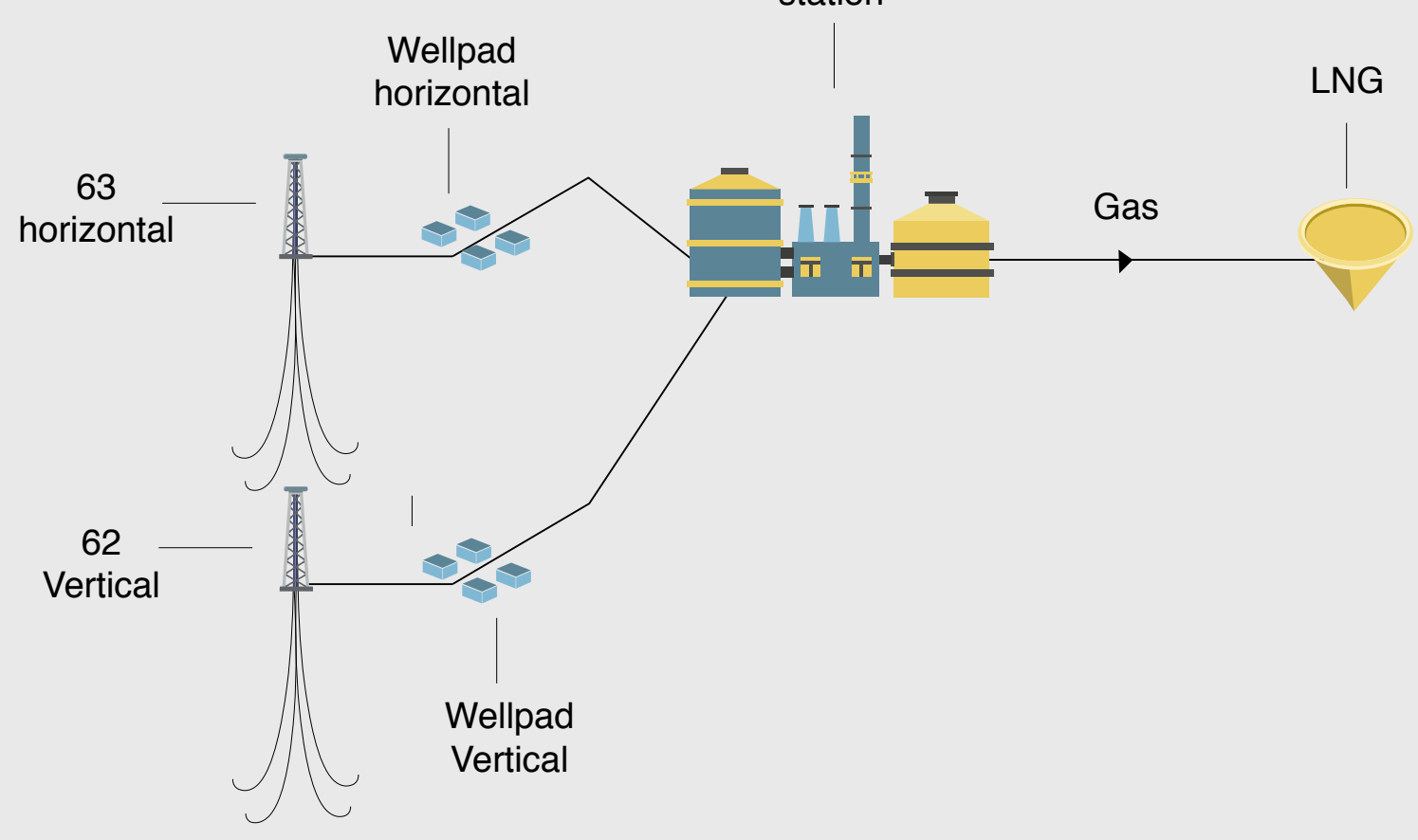

Figure A3-4. Development concept for a CBM project.

Source: IHS QUE\$TOR, KAPSARC research. 


\section{Annual production (gas) CBM China archetype project}

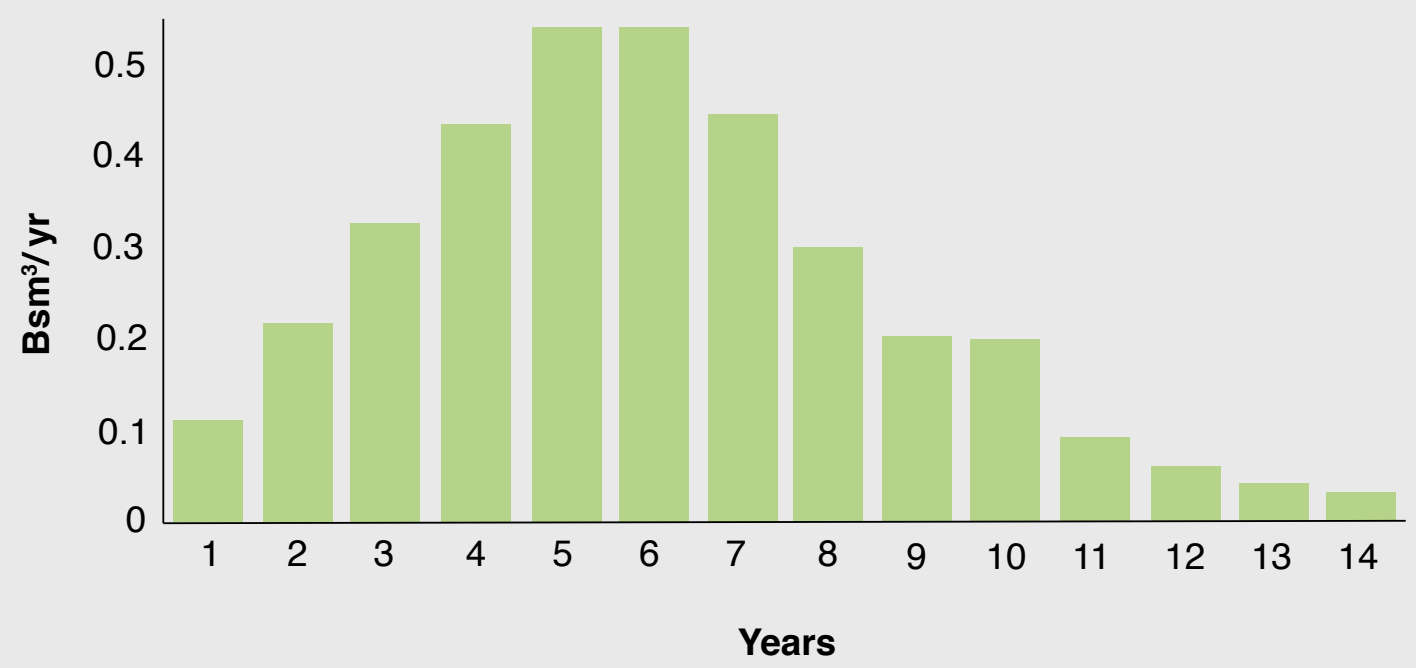

Figure A3-5. Production profile of an archetype CBM project.

Source: IHS QUE\$TOR, KAPSARC research.

Table A3-6. Estimated costs of an archetype CBM project.

\begin{tabular}{l|l|l|l|l|l|l}
$\begin{array}{l}\text { CAPEX } \\
\text { \$/mscm }\end{array}$ & $\begin{array}{l}\text { OPEX } \\
\text { \$/mscm }\end{array}$ & $\begin{array}{l}\text { Decom } \\
\text { \$/mscm }\end{array}$ & Total \$/mscm & $\begin{array}{l}\text { OPEX with } \\
\text { subsidies } \\
\mathbf{\$} / \mathbf{m s c m + s u b s}\end{array}$ & $\begin{array}{l}\text { Total with } \\
\text { subsidies } \\
\mathbf{\$} / \mathbf{m s c m + s u b s}\end{array}$ & $\begin{array}{l}\text { Number of } \\
\text { projects }\end{array}$ \\
\hline 100.4 & 79.7 & 12.9 & 193.0 & 47.2 & 160.5 & 54
\end{tabular}

Source: IHS QUE\$TOR, KAPSARC research. 
Table A3-7. CMM output and utilization.

\begin{tabular}{l|l|l|l|l|l|l|l|l|l|l|l} 
Indicators & $\mathbf{2 0 0 5}$ & $\mathbf{2 0 0 6}$ & $\mathbf{2 0 0 7}$ & $\mathbf{2 0 0 8}$ & $\mathbf{2 0 0 9}$ & $\mathbf{2 0 1 0}$ & $\mathbf{2 0 1 1}$ & $\mathbf{2 0 1 2}$ & $\mathbf{2 0 1 3}$ & $\mathbf{2 0 1 4}$ & $\mathbf{2 0 1 5}$ \\
\hline $\begin{array}{l}\text { CMM drainage, } \\
\text { bcm }\end{array}$ & 2.15 & 3.15 & 4.3 & 5.65 & 6.1 & 7.2 & 9.1 & 11.3 & 12.5 & 13.2 & 13.57 \\
\hline $\begin{array}{l}\text { CMM utilization, } \\
\text { bcm }\end{array}$ & 0.75 & 1.2 & 1.49 & 1.7 & 1.8 & 2.5 & 3.5 & 3.8 & 4.25 & 4.55 & 4.77 \\
\hline $\begin{array}{l}\text { Coal production, } \\
\text { Gton }\end{array}$ & 2.37 & 2.57 & 2.76 & 2.90 & 3.12 & 3.43 & 3.76 & 3.95 & 3.97 & 3.87 & 3.75 \\
\hline \begin{tabular}{l} 
Utilization, \% \\
\hline Gas volume, m3/t
\end{tabular} & 34.9 & 38.1 & 34.7 & 30.1 & 29.5 & 34.7 & 38.5 & 33.6 & 34.0 & 34.5 & 35.2 \\
\hline
\end{tabular}

Source: China Coal Information Institute. 


\section{About the Authors}

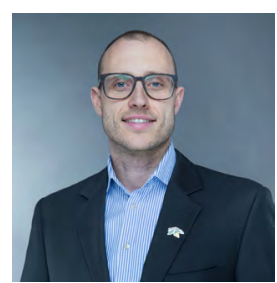

\section{Bertrand Rioux}

Bertrand is a research fellow developing energy systems models. He completed a master's thesis in computational fluid dynamics at KAUST.

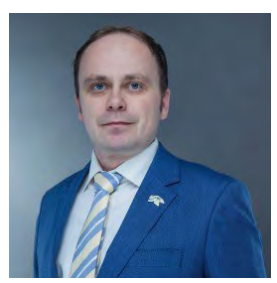

\section{Philipp Galkin}

Philipp is a research fellow specializing in the economic and policy aspects of energy supply and trade. He holds a Ph.D. in International Economic Relations and an MBA.

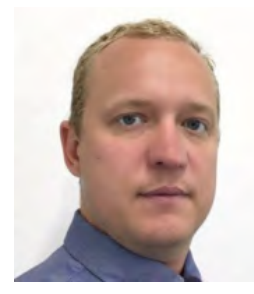

\section{Artem Malov}

Artem Malov is a former senior research associate at KAPSARC. He is an expert in cost estimation and facilities engineering with 14 years experience in energy.

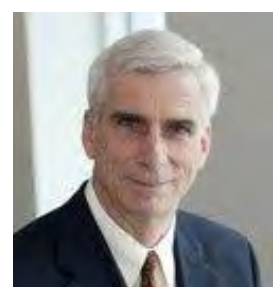

\section{Frederic Murphy}

Frederic is a senior visiting fellow and professor emeritus, Temple University. He has a Ph.D. in Operations Research and a B.A. in Mathematics from Yale University.

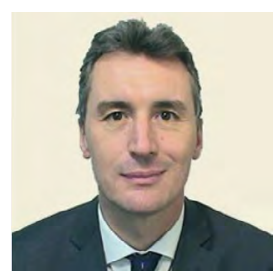

\section{Axel Pierru}

Axel is a senior research fellow and program director at KAPSARC. He has a Ph.D. in Economics from Pantheon-Sorbonne University.

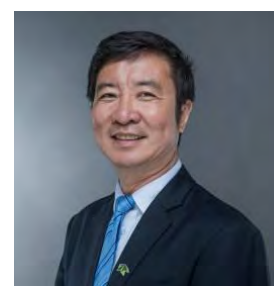

\section{Kang Wu}

Kang is a program director for Markets and Industrial Development at KAPSARC. He holds a Ph.D. in Economics and has many years of energy research and consulting experience focusing on Asia. 

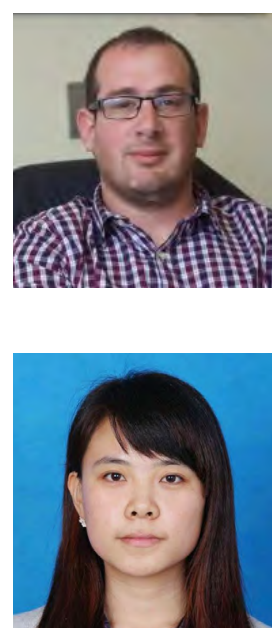

\section{Felipe Feijoo Palacios}

Felipe is a visiting fellow at KAPSARC and an assistant professor at the Pontifical Catholic University of Valparaiso. He has over 7 years of experience in energy systems modelling and holds a Ph.D. in Industrial Engineering from the University of South Florida.

\section{Yan Li}

Yan $\mathrm{Li}$ is a visiting researcher at KAPSARC. She is a Ph.D. candidate at the Academy of Chinese Energy Strategy, China University of Petroleum-Beijing.

\section{About the Project}

The KAPSARC Energy Model of China (KEM China) project began in 2014 to study energy and environmental issues in China. KEM China has been developed to understand China's energy economy and fuel mix, and how they are impacted by government intervention, as well as their interaction with global markets. It is a modular integrated mixed complementarity problem model that optimizes supply decisions, minimizing fuel and technology costs, while taking into account the effect of government regulation on prices and the environment. 


\section{Notes}

r. 
Notes

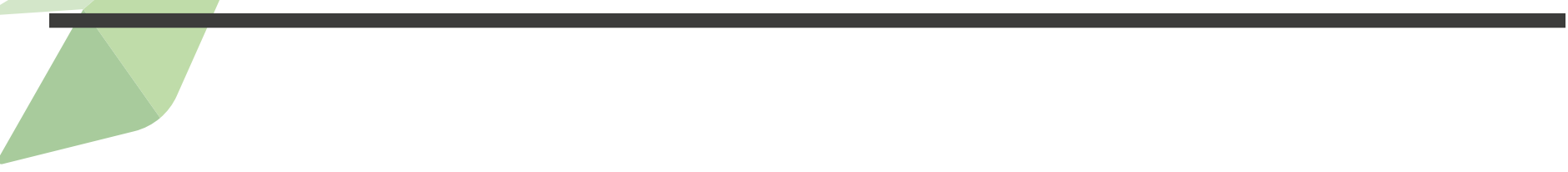


INAPSARC

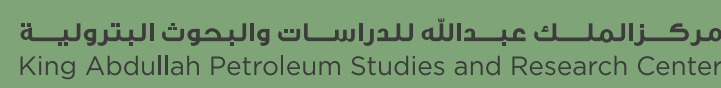

www.kapsarc.org 